\title{
Concentrations of phytoestrogens in conventional, organic and free-range retail milk in England
}

Article

Accepted Version

Creative Commons: Attribution-Noncommercial-No Derivative Works 4.0

Norskov, N. P., Givens, I., Purup, S. and Stergiadis, S. (2019) Concentrations of phytoestrogens in conventional, organic and free-range retail milk in England. Food Chemistry, 295. pp. 19. ISSN 0308-8146 doi:

https://doi.org/10.1016/j.foodchem.2019.05.081 Available at https://centaur.reading.ac.uk/83615/

It is advisable to refer to the publisher's version if you intend to cite from the work. See Guidance on citing.

To link to this article DOI: http://dx.doi.org/10.1016/j.foodchem.2019.05.081

Publisher: Elsevier

All outputs in CentAUR are protected by Intellectual Property Rights law, including copyright law. Copyright and IPR is retained by the creators or other copyright holders. Terms and conditions for use of this material are defined in the End User Agreement.

www.reading.ac.uk/centaur 
Central Archive at the University of Reading

Reading's research outputs online 
Concentrations of phytoestrogens in conventional, organic and free-range retail milk in England

Natalja P. Nørskov ${ }^{\mathrm{a}}$, Ian Givens ${ }^{\mathrm{b}}$, Stig Purup ${ }^{\mathrm{a}}$, Sokratis Stergiadis ${ }^{\mathrm{c} *}$

a Aarhus University, Department of Animal Science, AU-Foulum, Blichers Alle 20, P.O. Box 50, DK-8830 Tjele, Denmark

${ }^{\mathrm{b}}$ University of Reading, Institute for Food Nutrition and Health, Agriculture Building, P.O. Box 237, Earley Gate, Reading, RG6 6AR, United Kingdom

${ }^{c}$ University of Reading, School of Agriculture, Policy and Development, Animal, Dairy and Food Chain Sciences, Agriculture Building, P.O. Box 237, Earley Gate, Reading, RG6 6AR, United Kingdom

* Corresponding author: Sokratis Stergiadis, $\underline{\text { s.stergiadis@ @reading.ac.uk }}$

Keywords: isoflavones, lignans, equol, milk quality, organic, free-range 


\section{Highlights}

- Phytoestrogens in milk from three management systems were measured

- Organic milk contained more lignans, isoflavones and coumestants

- Phytoestrogen composition did not vary between free-range and conventional milk

- Summer milk contained more lignans and less isoflavones than winter milk

- Milk from different production systems may alter consumer phytoestrogen intake 


\begin{abstract}
The effect of dairy management system (conventional, CNV; organic, ORG; free-range, FRG) and month on retail milk phytoestrogen composition was assessed for 12 consecutive months. ORG milk contained more secoisolariciresinol, matairesinol, lariciresinol, sum of plant lignans, daidzein, genistein, formononetin, naringenin, equol, sum of isoflavones and coumestrol, than CNV and FRG milk. This may be explained by the higher supply of pasture, and grazed or ensiled clover, in ORG dairy diets. Seasonal variation in milk phytoestrogen concentrations was higher for ORG than CNV and FRG systems. Phytoestrogen composition did not vary between FRG and CNV milk. Consuming organic milk can increase intake of potentially beneficial lignans and isoflavonoids, and in particular equol; but, any effects on human health from such milk compositional differences cannot be implied.
\end{abstract}




\section{Introduction}

Milk is an important part of healthy and balanced diets, because it contains high biological value proteins, bioactive peptides, fatty acids, minerals, vitamins, and carotenoids, with multiple benefits in human health (Thorning, Raben, Tholstrup, Soedamah-Muthu, Givens, \& Astrup, 2016). Previous work has shown that milk also contains phytoestrogens, such as isoflavones, lignans and coumestans (Kuhnle, Delcaqulla, Aspinall, Runswick, Mulligan, \& Bingham, 2008), of which the potential effect in human health is not extensively investigated and nutritional recommendations are not available (Leitzmann, 2016). Phytoestrogens are plant secondary metabolites and involved in plant development and survival (Crozier, 2009). Lignans are bound to cell wall macromolecules, because they are formed during lignin synthesis and strengthening of the plant cell wall (Kuhnle, Dell'Aquila, Aspinall, Runswick, Mulligan, \& Bingham, 2009b). Linseed and grains, especially wheat and rye, are rich in lignans, which are located in the aleurone layer of the bran (Fardet, 2010; Kuhnle, et al., 2009b; Smeds, et al., 2007). In lower amounts, lignans also exist in fruits, vegetables, grasses and legumes (Adler, Purup, Hansen-Moller, Thuen, Gustavsson, \& Steinshamn, 2014; Kuhnle, et al., 2009a). Isoflavones are produced by Fabaceae Leguminosae plants, and perform various functions, providing mainly defense against pathogens (Adler, et al., 2014). Soybeans are the richest source of the isoflavones daidzein and genistein, whereas red clover is rich in formononetin and biochanin A, but has low daidzein and genistein concentrations (Mustonen, et al., 2009). White clover contains less total isoflavones than red clover, but more lignans and coumestans (Adler, et al., 2014; Andersen, Weisbjerg, Hansen-Moller, \& Sejrsen, 2009; Hojer, et al., 2012; Mustonen, et al., 2009; Steinshamn, Purup, Thuen, \& Hansen-Moller, 2008). The concentration of coumestans in plants increases in response to stress or diseases (Reed, 2016) and coumestrol has been found in 58 plants, being in high amounts in legumes, such as white clover, lucerne and peas (Reed, 2016). 
In cows, phytoestrogens are mostly metabolized in the rumen, and therefore the transfer

rates from feed to milk are small (Gagnon, et al., 2009; Njastad, Adler, Hansen-Moller, Thuen, Gustavsson, \& Steinshamn, 2014). The rumen metabolism of lignans, isoflavones and coumestans is complex and their degree of conversion varies among different phytoestrogens (Adler, et al., 2014; Heinonen, et al., 2001; Njastad, et al., 2014). Njastad et al. (2014) showed that plant isoflavones were extensively metabolized in the rumen $(70 \%$ and $90 \%$ of biochanin A and genistein, respectively) into intermediary compounds. Most of the formononetin and daidzein was also transformed in the rumen into the mammalian isoflavone equol (Njastad, et al., 2014). Rumen microorganisms also extensively metabolise plant lignans into the mammalian lignans enterodiol and enterolactone (Heinonen, et al., 2001; Njastad, et al., 2014), while animal studies and experiments with human fecal inoculum showed that secoisolariciresinol and matairesinol are also precursors to mammalian lignans (Heinonen, et al., 2001; Njastad, et al., 2014). Other plant lignans may be converted to secoisolariciresinol and matairesinol through intermediate reactions and thereby contribute to enterodiol and enterolactone synthesis (Heinonen, et al., 2001; Njastad, et al., 2014). There is a scarce information about coumestrol metabolism but its transformation in the rumen is rather limited (Njastad, et al., 2014). Further to their metabolism in the rumen, and during intestinal absorption, phytoestrogens are conjugated mainly with glucuronic and sulfonic acids and transferred to blood and milk as conjugates (Njastad, et al., 2014).

Phytoestrogens are found both in forages and concentrates of cows' diets. The phytoestrogens content in forage depends mainly on the botanical composition, but also plant part, maturity stage, season (Booth, et al., 2006; Hojer, et al., 2012; Kallela, Saastamoinen, \& Huokuna, 1987; Tsao, Papadopoulos, Yang, Young, \& McRae, 2006). Therefore, the milk phytoestrogen concentrations may be influenced by grassland management and dairy management system (Adler, et al., 2014; Adler, Purup, Hansen-Moller, Thuen, \& Steinshamn, 
2015; Hojer, et al., 2012). The concentration of isoflavones was higher in cow diets that contained red clover than other species (Andersen, et al., 2009; Hojer, et al., 2012; Njastad, et al., 2014). This may affect organic milk isoflavone concentrations because, in the absence of nitrogen fertilization of organic swards, UK organic dairy systems extansively rely on clover inclusion in pastures and silages to achieve high sward productivity (AHDB, 2012; Soil Association, 2018; Stergiadis, et al., 2015; Stergiadis, et al., 2012). The effect of dairy management system on milk phytoestrogens concentrations has been observed in Finland, Norway and Denmark (Adler, et al., 2015; Hoikkala, et al., 2007; Purup, 2005). Finnish organic retail milk contained more equol that conventional milk (Hoikkala, et al., 2007). In Norway, organic milk collected from farms' bulk-tanks had higher concentrations of formononetin, daidzein, equol, genistein, secoisolariciresinol, enterodiol and enterolactone, than conventional milk; moreover, milk produced during the indoor period contained more equol than milk from the outdoor period, whereas the opposite was observed for enterolactone (Adler, et al., 2015). In Denmark, the concentration of isoflavonoids in milk from organic dairy farms was higher than milk from conventional farms; presumably because of the higher contribution of legumes in organic dairy diets; notably, the content of equol in organic milk was approximately five times higher (Purup, 2005).

Although results from Finland, Norway and Denmark demonstrate strong management system and seasonal effects on isoflavone and lignan concentrations in milk, a similar assessment in the UK has not been performed. Previous work on milk fatty acid profiles demonstrates that composition of organic and conventional milk, may differ significantly between countries, thus highlighting the necessity for milk composition assessments in different countries separately (Butler, et al., 2011). The aim of the present work was (i) to investigate, for the first time, the effect of, and interactions between, dairy management system (including conventional, organic and free-range) and month, on the concentrations of lignans, 
isoflavones and coumestans in milk purchased from retail outlets in the United Kingdom, and (ii) assess the potential impact of consuming milk from different dairy management systems on phytoestrogen intake of consumers.

\subsection{Experiment/survey design}

Milk samples $(n=120)$ representing four brands of conventional $(\mathrm{CNV} ; \mathrm{n}=48)$ milk and four brands of organic (ORG; $n=48$ ) milk were collected monthly, over 12 months (March 2016 and February 2017), within an 8-km radius from the Whiteknights campus of the University of Reading. Brands were selected to represent suppliers that offer both CNV and ORG milk and have as high as possible market share. Two brands of milk certified as freerange (FRG; $n=24)$, which were the only two brands available when the survey took place, were also monthly collected during the same sampling dates from dairies in Lancashire and Gloucestershire. ORG milk was certified by Soil Association and FRG milk by the Free Range Dairy Pasture Promise. Only whole, pasteurized and homogenized milk was collected; CON and ORG milk was purchased from supermarkets while retail free-range milk was posted, in cold conditions, from the Free Range Network to the University of Reading. Milk from CNV and FRG systems were fat-standardised at approximately 35 and $37 \mathrm{~g} / \mathrm{kg}$ milk, respectively; this is a standard practice in the conventional UK dairy plants while standardization is not performed in the organic UK dairy supply chain. At the day of collection, the commercial bottle (typically made of high-density polyethylene) with the furthest "best before" date (hence the most recent on the shelf) was purchased to maximize freshness of the collected sample. This has been immediately transferred in cold conditions at the laboratories of the University of Reading and was aliquoted in several 30-ml sterile, screw-top, leak-free polypropylene containes and frozen at $-20^{\circ} \mathrm{C}$ until analysis. 


\subsection{Milk analysis}

One aliquote of 30-ml of each sample, packed with several ice packs into polysterene boxes and by using next day delivery in order to ensure samples remained frozen throughout transport, was sent to Aarhus University. Upon delivery, samples were immediately stored at $20^{\circ} \mathrm{C}$ and were analysed in the laboratory between January and May 2018. Quantitative measurements were performed using the following lignans and isoflavones standards: enterolactone, enterodiol, matairesinol, hydroxymatairesinol, secoisolariciresinol, lariciresinol, isolariciresinol, syringaresinol, medioresinol, pinoresinol, equol, naringenin, formononetin, chrysin, genistein, daidzein, glycitein, coumestrol, purchased from Plantech (Berksher, UK). The following isotope-labeled and deuterium-labeled internal standards were used: ${ }^{13} \mathrm{C}_{3}-$ enterolactone, ${ }^{13} \mathrm{C}_{3}$-enterodiol, equol D4 from Toronto Research Chemicals (Toronto, Canada) and genistein-d4 and daidzein-d3 from Cambridge Isotop Laboratories, Inc. (Andover, MA, USA). For the enzymatic hydrolysis, $\beta$-glucuronidase type H-1 from Helix pomatia was purchased from Sigma-Aldrich (St. Louis, MO, USA). All solvents used were of HPLC grade.

\subsubsection{Preparation and storage of standards}

All lignan standards were dissolved in pure acetonitrile and all isoflavones standards were dissolved in pure methanol in concentration of $1 \mathrm{mg} / \mathrm{mL}$ and kept at $-80{ }^{\circ} \mathrm{C}$, except for genistein-D4 and daidzein-d3 internal standards, which were dissolved in acetonitrile in concentration $100 \mu \mathrm{g} / \mathrm{mL}$ and $60 \mu \mathrm{g} / \mathrm{mL}$ respectively. The working solutions of lignan internal standards were prepared in concentration of $10 \mu \mathrm{g} / \mathrm{mL}$ of ${ }^{13} \mathrm{C}_{3}$-enterolactone, $5 \mu \mathrm{g} / \mathrm{mL}$ of ${ }^{13} \mathrm{C}_{3}$ enterodiol and $50 \mu \mathrm{g} / \mathrm{mL}$ of equol-d4. For non-labeled standards, one working solution contained all lignan and equol standards and another working solution contained other isoflavones in the concentration of $400 \mathrm{ng} / \mathrm{mL}$. These working solutions were used for preparation of standard curves and spiking of milk samples. The working solution and the standard curves were kept at $-80{ }^{\circ} \mathrm{C}$ at all times. 
The milk samples (kept at $-20{ }^{\circ} \mathrm{C}$ before the analyses) were incubated in water bath at

$30{ }^{\circ} \mathrm{C}$ for $60 \mathrm{~min}$ and afterwards immediately shaken for $10 \mathrm{~min}$. Five $\mathrm{ml}$ of milk sample was transferred to $15 \mathrm{~mL}$ tube and $10 \mu \mathrm{L}$ of the internal standards, ${ }^{13} \mathrm{C}_{3}$-enterolactone, ${ }^{13} \mathrm{C}_{3^{-}}$ enterodiol, genistein-d4, daidzein-d3 and equol-d4 were added and mixed for 5 min. The samples were then centrifuged for $20 \mathrm{~min}$ at $4^{0} \mathrm{C}$ at 3,500 $\times \mathrm{g}$. One $\mathrm{ml}$ of the supernatant was transferred to a new tube to which $0.5 \mathrm{~mL}$ of enzymes were added. Further sample hydrolyses and clean-up were performed according to Norskov, Olsen, Tjonneland, Bolvig, Laerke, \& Knudsen (2015) with minor modification. Lignans and isoflavones were eluted with $200 \mu \mathrm{L}$ of acetonitrile from C18 plates and diluted with $600 \mu \mathrm{L}$ of MilliQ water and analyzed using LCMS/MS.

\subsubsection{LC-MS/MS equipment and method}

The LC-MS/MS measurements were performed on microLC 200 series from Eksigent/AB Sciex (Redwood City, CA, USA) and QTrap 5500 mass spectrometer from AB Sciex (Framingham, MA, USA) according to Norskov et al. (2015). The compound dependent parameters were optimized for each compound by syringe infusion of pure standard and shown in Appendix (Table A1). The data analysis was performed in Analyst software 1.6.2 from AB Sciex (Framingham, MA, USA).

\subsubsection{Calibration curves and quantification}

Calibration curves had 7-12 points depending on the analyte. The mixture of pure standards were prepared in $25 \%$ acetonitrile in the range of $0.0244-100 \mathrm{ng} / \mathrm{mL}$ for lignans, $0.39-200 \mathrm{ng} / \mathrm{mL}$ for equol (see Appendix, Figure A1), and $0.00977-5 \mathrm{ng} / \mathrm{mL}$ for all other isoflavones (see Appendix, Figure A2). The final concentrations were $25 \mathrm{ng} / \mathrm{mL}$ for ${ }^{13} \mathrm{C}_{3^{-}}$ enterolactone was, $12.5 \mathrm{ng} / \mathrm{mL}$ for ${ }^{13} \mathrm{C}_{3}$-enterodiol, $60 \mathrm{ng} / \mathrm{mL}$ for daidzein $\mathrm{D} 3,30 \mathrm{ng} / \mathrm{mL}$ for 
genistein-d4 and $200 \mathrm{ng} / \mathrm{mL}$ for equol-d4. The analyte/internal standard concentration ratio was plotted against the analyte/internal standard peak area ratio as a linear regression curve with $1 / x$ weighting. The quantification of the lignans, enterolactone, matairesinol and pinoresinol was performed using ${ }^{13} \mathrm{C}_{3}$-enterolactone as internal standard; and that of enterodiol, hydroxymatairesinol, secoisolariciresinol, lariciresinol, isolariciresinol, syringaresinol and medioresinol using ${ }^{13} \mathrm{C}_{3}$-enterodiol as internal standard. The quantification of isoflavones, daidzein and glycitein was performed using daidzein-d3 as internal standard; and that of genistein, naringenin, formononetin, chrysin and coumestrol using genistein-d4 as intenal standard. Equol was quantified using equol-d4 as internal standard. The lower limit of quantitation (LLOQ) was accepted as the lowest standard on the calibration curve if the analyte response was at least 5 times the response of the blank sample. The highest standard defined the upper limit of quantitation (ULOQ). All calibration curves showed good linearity throughout the used range of concentration with LLOQ accuracy varying from 88 to $110 \%$ and precision below 20\%, and ULOQ accuracy from 90 to $105 \%$ and precision below $15 \%$. The LLOQ and ULOQ and the corresponding regression coefficients for each isoflavone is listed in the Appendix (Table A2), and for lignans in (Norskov, et al., 2015). The representative chromatogram of the milk sample, as well the extracted ion chromatograms of each lignan and isoflavone, are shown in the Appendix (Figure A3 and A4, respectively).

\subsubsection{Method validation}

Method was validated by spiking internal standards and lignan and isoflavone standards in the beginning of the sample preparation procedure (addition of standards to $5 \mathrm{~mL}$ of milk sample) to the experimental milk samples containing the lowest possible concentration of lignans and isoflavones; recovery was then calculated using the internal standard procedure, as described above. The recovery of enterolactone and enterodiol was $105 \% \pm 3 \%$ and that of plant lignans (matairesinol, hydroxymatairesinol, secoisolariciresinol, lariciresinol, 
isolariciresinol, syringaresinol, medioresinol and pinoresinol) was $75 \% \pm 6 \%$. The recovery of equol was $112 \% \pm 3 \%$ and the recovery of other isoflavones were $95 \% \pm 10 \%$. Precision and intra-batch variation (based on 5 replicated measurements) were within $15 \%$. Further, the validation included the detection of possible lignans and isoflavones of interest in the enzyme mixture used for hydrolyses. Only trace amounts of formononetin $(0.004 \mathrm{ng} / \mathrm{mL})$, glycitein (0.006 ng/mL), naringenin $(0.04 \mathrm{ng} / \mathrm{mL})$, genistein $(0.05 \mathrm{ng} / \mathrm{mL})$, daidzein $(0.009 \mathrm{ng} / \mathrm{mL})$, enterolactone $(0.001 \mathrm{ng} / \mathrm{mL})$, secoisolariciresinol $(0.002 \mathrm{ng} / \mathrm{mL})$ and lariciresinol $(0.03 \mathrm{ng} / \mathrm{mL})$ were detected, and no coumestrol, equol, chrysin, isolariciresinol, enterodiol, matairesinol, hydroxymatairesinol, syringaresinol, medioresinol and pinoresinol were detected.

\subsection{Statistical analysis}

Linear mixed effects models in GenStat $17^{\text {th }}$ Edition (VSN International, UK) were used for the Analysis of Variance (ANOVA) (Residual maximum likelihood analysis; REML; (Gilmour, Thompson, \& Cullis, 1995)). Fixed factors were the management system (Conventional, CNV; Organic, ORG; Free-Range, FRG) and month (March 2016 - February 2017). To investigate the effect of the interaction between management system and month, a sub-set including only ORG and CNV milk has been created (excluding FRG milk) and a REML analysis was carried out using management system, month and their interaction as fixed factors. Every milk sample was given a unique milk ID (representing the combination of brand/retailer and management) and this was used as random factor in both REML analyses. The analysis derived and P-value and the effect of the main treatments was declared significant at $P<0.05$; tendencies were declared at $0.05<P<0.10$. Normality plots were used for performing the residual diagnostics of the model and data did not deviate from normality. Follow up pairwise comparison of means $(P<0.05)$ in cases that the effect of a fixed factors showing a significant effect were performed using Fisher's Least Significant Difference test. 


\subsection{Overall milk concentrations of phytoestrogens}

201

The concentration of plant isoflavones in milk was 5-8 times higher compared with

202

203

204

205

206

207

208

209

210

211

212

213

214

215

216

217

218

plant lignans and coumestrol, averaging $5.95 \mathrm{ng} / \mathrm{mL}$ (ranging 1.21-12.85 ng/mL) across the management systems; whereas the average plant lignan concentration was $0.90 \mathrm{ng} / \mathrm{mL}$ (ranging 0.51-1.64 ng/mL). The average equol and enterolactone concentrations was $203.1 \mathrm{ng} / \mathrm{mL}$ (ranging 4.3-794.4 ng/mL), and $61.9 \mathrm{ng} / \mathrm{mL}$ (ranging 32.9-138.9 ng/mL), respectively, across the management systems.

\subsection{Dairy management system and milk phytoestrogens composition}

The effect of dairy management system was significant for secoisolariciresinol, matairesinol, lariciresinol, total plant lignans, daidzein, genistein, formononetin, naringenin, total plant isoflavones, equol, total isoflavones and coumestrol (Table 1). ORG milk contained

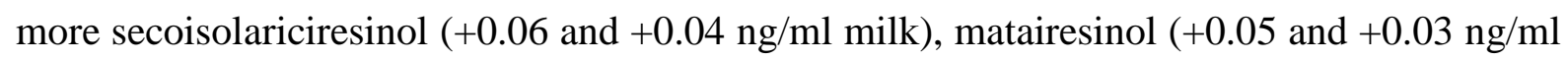
milk), lariciresinol $(+0.14$ and $+0.14 \mathrm{ng} / \mathrm{ml}$ milk $)$, total plant lignans $(+0.26$ and $+0.16 \mathrm{ng} / \mathrm{ml}$ milk), daidzein $(+1.74$ and $+1.72 \mathrm{ng} / \mathrm{ml}$ milk), genistein $(+1.49$ and $+1.47 \mathrm{ng} / \mathrm{ml} \mathrm{milk})$, formononetin $(+1.01$ and $+1.01 \mathrm{ng} / \mathrm{ml} \mathrm{milk})$, naringenin $(+0.13$ and $+0.12 \mathrm{ng} / \mathrm{ml} \mathrm{milk})$, total plant isoflavones $(+4.64$ and $+4.69 \mathrm{ng} / \mathrm{ml} \mathrm{milk)}$, equol $(+347$ and $+345 \mathrm{ng} / \mathrm{ml} \mathrm{milk})$, total isoflavones ( +352 and $+349 \mathrm{ng} / \mathrm{ml} \mathrm{milk})$ and coumestrol $(+0.35$ and $+0.37 \mathrm{ng} / \mathrm{ml} \mathrm{milk})$, than FRG and CNV milk (Table 1). The differences in individual lignan or isoflavonoid concentrations between CNV and FRG milk was not significant (Table 1).

\subsection{Sampling month and milk phytoestrogens composition}

The effect of month was significant for secoisolariciresinol, matairesinol, lariciresinol, hydroxymatairesinol, total plant lignans, enterolactone, enterodiol, total mammalian lignans, daidzein, genistein, formononetin, total plant isoflavones and total isoflavones (Table 2). Milk concentrations of secoisolariciresinol, matairesinol, lariciresinol and total plant lignans were 
increased during May-October than during March-April and November-February, with differences between individual months not always being statistically significant (Table 2). In contrast, concentrations of hydroxymatairesinol in milk were higher in March and DecemberFebruary, when compared with the period April-November, but differences between individual months were not always statistically significant (Table 2). Milk concentrations of enterolactone, total mammalian lignans and total lignans were increased during May-August, than during March and December-February and had intermediate values during the other months (Table 2). Milk concentrations of enterodiol in milk were increased during May and July-October, than during April, November and February and had intermediate values during the other months (Table 2). Milk concentrations of daidzein in milk were increased during August and October, although this was only statistically significant when compared with June and Jan-Feb (Table 2). Milk concentrations of genistein in milk were increased during MarchApril and October-November, when compared with the period May-June; their values were intermediate during the other months (Table 2). Milk concentrations of glycitein were higher during March-May, than during the period of June-July and November and had intermediate values during the other months (Table 2). Concentrations of milk total plant isoflavones had highest values during March, lowest values in June and intermediate values during the other months, but differences between individual months was not always statistically significant. Milk concentrations of formononetin were increased during March, August and November, when compared with May-June; while its values were intermediate during the other months (Table 2). Milk equol and total isoflavone concentrations were increased during March and October-February than during April-September; but differences between individual months were not always statistically significant (Table 2).

\subsection{Interactions between management system and sampling month on milk phytoestrogens} composition 
The effects of management system $\times$ month interaction was significant for daidzein, genistein, formononetin, equol and total isoflavones (Figure 1), secoisolariciresinol, matairesinol, lariciresinol, total plant lignans, enterolactone, enterodiol, total mammalian lignans and total lignans (Figure 2). Milk daidzein, genistein, formononetin, equol and total isoflavone concentrations were higher in ORG than in CNV milk, throughout the year, but the extent of the differences was fluctuating throughout the season; the highest differences were observed in November-February, for equol and total isoflavones; in August-October, for daidzein; August-November for Genistein; and November and March for formononetin (Figure 1). The management system $\times$ month interaction did not have a significant effect on milk concentrations of hydroxymatairesinol, glycitein, naringengin and coumestrol. Milk concentrations of secoisolariciresinol and lariciresinol were higher in ORG than in CNV milk in June-October (Figure 2). Milk concentrations of matairesinol increased in ORG milk during May-September, when compared with CNV milk, while the same was observed for total plant lignans, by also extending this significant difference to April (Figure 2). Concentrations of enterolactone, mammalian lignans and total lignans were increased in ORG milk, when compared with CNV milk, during June, August and December-February (Figure 2). Milk concentrations of enterodiol were higher in ORG than CNV milk during March, May-August and January (Figure 2). bovine milk (Adler, et al., 2014; Adler, et al., 2015; Andersen, et al., 2009; Hojer, et al., 2012; mammalian metabolism of plant isoflavones and lignans, and in particular formononetin, daidzein, secoisolariciresinol and matairesinol (Njastad, et al., 2014). Enterodiol (another 
mammalian lignan) was found in lower concentrations, as this is an intermediate in the process of enterolactone synthesis from plant lignans (Njastad, et al., 2014). The concentration of plant lignans secoisolariciresinol and matairesinol was lower compared with other studies (Adler, et al., 2014; Adler, et al., 2015; Steinshamn, et al., 2008), whereas the concentration of plant isoflavones, genistein, daidzein and formononetin was comparable (Adler, et al., 2015; Steinshamn, et al., 2008). Milk coumestrol concentration was low, but similar to previous work (Adler, et al., 2014; Adler, et al., 2015). The high variation in the concentration of equol and enterolactone between different studies imply that milk phytoestrogen concentrations may be influenced by a combination of genetics, diets and/or other management practices. Differences between studies are also because milk samples are collected at contrasting stages of the dairy supply chain, e.g. retail milk in the current work and milk from individual cows or farm bulktank in other studies (Adler, et al., 2014; Adler, et al., 2015; Steinshamn, et al., 2008). Milk chemical composition, including phytoestrogens, is strongly influenced by animal genetics and farm diets, when milk is collected from individual cows or farms. In contrast, milk collected at retail level represents the average composition of milk from each management system, resulting from mixing milk from a large numbers of farms prior to processing and packaging. This dilutes any extreme values from individual cows or herds that may be fed diets with strong effect on milk phytoestrogens concentrations. To our knowledge, this is the first study to measure lariciresinol, hydroxymatairesinol, glycitein and naringenin in bovine retail milk.

\subsection{Dairy management system and milk phytoestrogens composition}

\subsubsection{Organic milk}

Differences in the concentrations of individual lignans and isoflavones between ORG and $\mathrm{CNV}$ milk might be caused by the contrasting diets in these management systems. The 
pasture. White and red clover are commonly used in ORG dairy diets in the UK (AHDB, 2012;

Soil Association, 2018; Stergiadis, et al., 2015; Stergiadis, et al., 2012). Fresh or ensiled dietary

clover increases feed transfer rates from the rumen (Dewhurst, Evans, Scollan, Moorby, Merry, \& Wilkins, 2003; Stergiadis, et al., 2018), thus subsequently reducing the time feed is available to rumen microbes and the conversion of secoisolariciresinol (and other plant lignans) to enterolactone and enterodiol.

The higher concentration of secoisolariciresinol in ORG compared to CNV and FRG

milk is in agreement with Adler et al. (2015). However, management system did not affect concentrations of enterodiol and enterolactone (mammalian lignans), as previously reported (Njastad, et al., 2014), nor the sum of lignans, in the present work. This is in contrast with Adler et al. (2015), who found higher concentrations of enterolactone and enterodiol and lignans in ORG milk. The higher presence of secoisolariciresinol and matairesinol, precursors to enterolactone, in ORG milk in this study, may indicate a higher secoisolariciresinol dietary supply from the clover-based ORG dairy diets (AHDB, 2012; Soil Association, 2018). In addition, grain lignans are bound to cell wall macromolecules of the bran (Fardet, 2010) and have low bioavailability, thus potentially reducing their conversion to enterolactone. Therefore, the bioavailability of secoisolariciresinol may be lower in high-grain CNV diets, typical in the UK CNV dairy systems (Stergiadis, et al., 2012), and this reduces their concentrations in milk. In contrast to the present work, Njastad er al. (2014) found similar concentrations of secoisolariciresinol, and matairesinol in ORG and CNV milk. The contrasting effects between studies may result from the variant composition of concentrates in CNV diets, e.g. made up of different grains and thereby altering supply of plant lignans, which are precursors to enterolactone. For example, plant lignans in wheat, which is the main grain used in UK dairy diets, is higher than in oat and barley (Smeds, et al., 2007), which are also used but in lesser 
extent. However, background information of grain contribution and composition in the dairy diets of different management systems was not available in the current work.

The concentration of hydromatairesinol and glycitein was similar between the management systems, potentially because hydroxymatairesinol is predominant lignan in oats and barley (Smeds, et al., 2007); feeds that contribute less in cow diets than other grains (e.g. wheat, maize) and only minor differences are expected between diets in the different management systems. Given that hydroxymatairesinol in milk may originate from dietary hydroxymatairesinol, that has been transferred to milk, or synthesized from matairesinol through phase I metabolism (Niemeyer, Honig, Kulling, \& Metzler, 2003).

Similar to the present work, Adler et al. (2015) showed higher concentration of isoflavones, daidzein, genistein, and formononetin in $\mathrm{ORG}$, than $\mathrm{CNV}$, milk. Legumes, including white and red clover which are extensively used in ORG dairy diets (AHDB, 2012; Soil Association, 2018; Stergiadis, et al., 2015; Stergiadis, et al., 2012), are richer in isoflavones (including daidzein, genistein and formononetin) and coumestrol, than grass and grains (Adler, et al., 2014; Kuhnle, et al., 2008). This increases their dietary intakes and the subsequent amounts that are absorbed and transferred into milk (Njastad, et al., 2014). Previous studies in Finland, France and Norway demonstrated that the high concentration of isoflavones, and especially equol, in ORG milk were because of higher intakes of ensiled or fresh red clover (Adler, et al., 2014; Adler, et al., 2015; Andersen, et al., 2009; Antignac, Cariou, Le Bizec, \& Andre, 2004; Hoikkala, et al., 2007; Hojer, et al., 2012; Steinshamn, et al., 2008). Red clover is rich in daidzein, formononetin, and biochanin A, which are precursors of equol (Mustonen, et al., 2009), and the most common legume for silage making in the ORG dairy farms in the UK (AHDB, 2012). Equol concentrations in ORG and CNV milk in the study of Hoikalla et al. (2007) were very similar (411 and $62 \mathrm{ng} / \mathrm{ml}$, respectively) to those measured in the current 
work (411 and $64 \mathrm{ng} / \mathrm{ml}$, respectively), although those in retail milk in the study of Antignac et al. (2004) were lower (191 and $36 \mathrm{ng} / \mathrm{mL}$, respectively).

ORG dairy cow diets also have a higher forage:concentrate ratio than CNV diets throughout the year (Soil Association, 2018; Stergiadis, et al., 2012). Steinshamn et al. (2008) found that concentrate supplementation reduces the intake of most phytoestrogens, including equol, biochanin A and daidzein. This may be an additional reason for their lower concentration in CNV milk, as the lower intakes would reduce their outputs in milk, as well as the amounts of in vivo synthesised equol (Njastad, et al., 2014).

\subsubsection{Free-range milk}

In the present work, the phytoestrogen concentrations did not differ between CNV and FRG milk, which is probably due to small feeding differences between these two management systems. Similar findings, and extensive potential explanations, have been recently published for milk fatty acids, which are also strongly influenced by cow diet (Stergiadis, Berlitz, Hunt, Garg, Givens, \& Kliem, 2019). Farm management practices have not been recorded in the present work, and there is limited information available to describe FRG management, but similar diets, in terms of forage:concentrate ratio and forage species used, between CNV and FRG farms may explain the similar milk concentrations of lignans and isoflavonoids.

\subsection{Seasonal effect on milk phytoestrogens composition}

In UK farms that use grazing as a feeding practice, cows would typically turnout to pasture around late March-beginning of April and access will be provided until approximately late-October, with grazing intake being maximum between May and August (AHDB, 2011). In late October-early November, cows would be taken indoors, and fed with conserved forages and concentrates (AHDB, 2011).

In the present work, milk lignan concentrations (including enterolactone, secoisolariciresinol, and matairesinol and lariciresinol), were higher during the 
outdoors/grazing period, as previously shown in Norway for enterolactone, secoisolariciresinol and matairesinol (Adler, et al., 2015). This may result from the higher concentrations and bioavailability of lignans in the pastures, which contribute more in cow diets during the grazing season. In the present work, $40 \%$ of samples were ORG and cows were expected to graze pastures rich in legumes, and in particular clover (AHDB, 2012; Soil Association, 2018; Stergiadis, et al., 2015; Stergiadis, et al., 2012). In contrast, the higher concentration of hydroxymatairesinol was higher during indoor period, which is expected as the main source of hydroxymatairesinol in cow diets are the concentrates rather than the forages.

Milk concentrations of sum of and individual isoflavones (including daidzein, genistein, formononetin, naringenin and equol) were higher during the typical indoor season, thus aligning with previous results for equol, daidzein, formononetin and the sum of isoflavones, although previous findings were not always statistically significant (Adler, et al., 2015). It is possible that the contribution of clover, which is rich in isoflavones (Steinshamn, et al., 2008), is higher in silages than in pasture because silage swards are harvested when clover biomass contribution is relatively high. Milk isoflavone concentration is strongly influenced by silage botanical composition (Hojer, et al., 2012), something that might have contributed to seasonal differences in the present work. Red clover is richer in formononetin, a precursor to equol, than other legumes such as white clover, timothy, meadow fescue and birdsfoot trefoil (Hojer, et al., 2012). Given that red clover is a typical legume for silage making in the UK, while pastures contain substantial amounts of white clover (AHDB, 2012; Soil Association, 2018), the grass/red-clover silage (fed during the indoor period) would provide more dietary daidzein, genistein, formononetin and biochanin A than grass/white-clover pastures (Steinshamn, et al., 2008). In addition, the pasture and silage concentrations of daidzein, genistein, formononetin and biochanin A are influenced by plant growth stage, and the biomass leaf:stem ratio (Booth, et al., 2006; Hojer, et al., 2012; Tsao, et al., 2006). 
Isoflavones are in higher concentrations in leaves than in stems (Tsao, et al., 2006) and, given that clover is harvested for silage making at strategic times when leaf:stem ratio is higher than the typical leaf:stem ratio when cows are grazing, clover-based silages would provide more dietary isoflavones than grass-clover pastures. The higher contribution of soybean meal, which is rich in daidzein and genistein, in cow diets during the indoor period in the CNV and FRG systems may explain the increase in milk isoflavone concentrations. Genistein, glycitein, daidzein showed similar, but not as strong, seasonal patterns as equol. This indicates that equol concentrations represent the combined effect of clover silage and soybean supplementation, while one of these factors may have less impact in the other isoflavones.

\subsection{Interaction between management system and season on milk phytoestrogens composition}

Seasonal variation of phytoestrogens was stronger in the ORG, than in CNV, milk. This is because the main driver for milk phytoestrogen concentrations is cow diet (Adler, et al., 2014; Njastad, et al., 2014), and dairy diets are more diverse throughout the year in ORG than in CNV systems. In ORG herds, cows ought to graze at least $60 \%$ of their dry matter intake during the grazing season, and the typical grass/clover swards have variant contribution of clover between different months (AHDB, 2012; Soil Association, 2018). Cows in CNV herds also typically graze between April-October, but the intakes of grazed forage would be lower than in ORG cows (Stergiadis, et al., 2012), while clover is not commonly used, and the relative impact on seasonal variation will be less pronounced. In addition, highly-intensive dairy farms (Stergiadis, et al., 2012), which also contribute to the CNV retail milk pool, do not allow cows to graze and offer similar diets throughout the year (based on conserved forage and concentrates), thus further reducing the seasonal effect (Stergiadis, et al., 2012).

ORG, than in CNV milk, during parts of the grazing season, but not during the indoor season.

The main driver of the concentrations of these lignans in milk is their dietary intake (Adler, et 
al., 2015). Clover-containing pasture can be a main source (Adler, et al., 2014), and the higher pasture intakes of ORG cows during the grazing season may explain this finding. This difference is reduced in winter, when both ORG and CNV cows are housed indoors and receive conserved forages and concentrates; although ORG silage may still supply more clover than CNV silage.

Concentrations of daidzein, genistein, formononetin, equol and sum of isoflavones were higher in the ORG, than in $\mathrm{CNV}$, throughout the year, and in particular during the indoor season. Provided that red clover is the main driver for milk equol concentrations, and ORG silages are made mainly using red clover, while ORG grazing swards may also contain substantial amounts of white clover (AHDB, 2012), it is expected that winter diets may contain more red clover. This increases the supply of daidzein, formononetin and biochanin A (Steinshamn, et al., 2008) for equol synthesis in the rumen during the indoor period. In addition, a higher contribution of overall clover and leaf:stem ratio, both factors known to increase isoflavones supply (Adler, et al., 2014; Tsao, et al., 2006), is expected in the ensiled forage than in grazed sward, because harvest for silage takes place when there is a higher clover biomass and leaf:stem ratio, compared to that grazed by cows in grass-clover pastures.

Enterolactone concentrations were not influenced by the management system but ORG milk contained more enterolactone during summer, similarly to other plant lignans, but less enterolactone during winter, when compared with CNV milk. The intakes of plant lignans, which are precursors to enterolactone, potentially decrease at higher rates during winter period in ORG dietsp; while rumen microbes may become more efficient in metabolising feed phytoestrogens over time (Njastad, et al., 2014).

4.5 Potential impact of consuming milk from different dairy management systems on phytoestrogen intakes of UK consumers 
447 liquid milk consumption (average; including whole, semi-skimmed and skimmed milk) for males and females was $275 \mathrm{~g}$ /day for children 1.5-3.0 years, $187 \mathrm{~g} /$ day for children 4-10 years, $110 \mathrm{~g} /$ day for teenagers 11-18 years, $125 \mathrm{~g} /$ day for adults 19-64 years, and $181 \mathrm{~g} /$ day for adults over 65 years. Antignac et al. (2004) showed that whole and skim milk have similar phytoestrogen concentrations in France, and we assume that phytoestrogen profile measured in whole milk in the present work will represent the profiles of other available retail liquid milk in the UK (semi-skimmed, skimmed). Therefore, under the current intakes of liquid milk (Bates, et al., 2014), a change from CNV to ORG milk will increase the intakes of equol by $95.3 \mu \mathrm{g} /$ day in children $1.5-3.0$ years (from 17.5 to $112.8 \mu \mathrm{g} /$ day), $68.7 \mu \mathrm{g} /$ day in children $4-$ 10 years (from 12.6 to $81.3 \mu \mathrm{g} /$ day), $49.3 \mu \mathrm{g} /$ day in teenagers $11-18$ years (from 9.0 to 58.3 $\mu \mathrm{g} / \mathrm{day}$ ), $47.3 \mu \mathrm{g} / \mathrm{day}$ in adults $19-64$ years (from 8.7 to $56.0 \mu \mathrm{g} / \mathrm{day}$ ), and $64.0 \mu \mathrm{g} / \mathrm{day}$ in adults over 65 years (from 11.7 to $75.7 \mu \mathrm{g} / \mathrm{day}$ ). Across all ages and genders, a change from CNV to ORG liquid milk would also increase the intakes of secoisolariciresinol by $0.01 \mu \mathrm{g} /$ day (from 0.03 to $0.04 \mu \mathrm{g} /$ day); matairesinol by $0.01 \mu \mathrm{g} /$ day (from 0.02 to $0.03 \mu \mathrm{g} / \mathrm{day}$ ); lariciresinol by $0.03 \mu \mathrm{g} /$ day (from 0.06 to $0.09 \mu \mathrm{g} / \mathrm{day}$ ); daidzein by $0.32 \mu \mathrm{g} /$ day (from 0.18 to $0.50 \mu \mathrm{g} / \mathrm{day}$ ); genistein by $0.27 \mu \mathrm{g} /$ day (from 0.16 to $0.43 \mu \mathrm{g} /$ day); formononetin by $0.18 \mu \mathrm{g} / \mathrm{day}$ (from 0.02 to $0.20 \mu \mathrm{g} /$ day); naringenin by $0.03 \mu \mathrm{g} / \mathrm{day}$ (from 0.03 to $0.06 \mu \mathrm{g} / \mathrm{day}$ ) and coumestrol by 0.06 $\mu \mathrm{g} / \mathrm{day}$ (from 0.02 to $0.08 \mu \mathrm{g} / \mathrm{day}$ ).

The most substantial effect of switching to ORG milk on phytoestrogen intakes is therefore observed for equol, while differences in intakes of other phytoestrogens are rather low $(<32 \mu \mathrm{g} /$ day). Potential health benefits from equol and other phytoestrogen intake, including lower risk for type-2 diabetes, cardiovascular disease, and hormone-dependent cancers, action against osteoporosis and metabolic syndrome and reduction of menopausal symptoms have been discussed in systematic reviews (Adlercreutz, 2007; Fardet, 2010; 
471 Jungbauer \& Medjakovic, 2014; Leitzmann, 2016). A meta-analysis of prospective cohort 472 studies, and a systematic review, established that for every $10 \mathrm{mg} /$ day increase in the intake of phytoestrogens, there is a 5\% decrease on cardiovascular disease risk (Leitzmann, 2016; Wang,

474 Ouyang, Liu, \& Zhao, 2014). However, the effects of phytoestrogens on human health have not been sufficienctly studied for the development of nutritional recommendations (Leitzmann, 2016). Although ORG milk contained more of the individual isoflavones and lignans, nutritional recommendations and larger cohort and epidemiological studies to enlighten the potential effects of phytoestrogens in human health (and the relative amounts required) are not available. Therefore, in the present work it is not possible to conclude on any potential implications of these differences on human health.

Organic retail milk had higher concentrations of the lignans secoisolariciresinol, matairesinol, and lariciresinol, the isoflavones daidzein, genistein, formononetin, naringenin and equol, and the coumestant coumestrol, when compared with milk from conventional or free-range systems. There was a significant effect of management system on isoflavones and coumestrol throughout the year but the effect on lignans was significant only during the typical UK grazing season. In the present work, milk was collected at retail outlets and collecting detailed information on dairy practices at farm level was not possible (beyond the label

certification). However, differences in phytoestrogen composition may be a consequence of differing cow diets, and most likely and effect of the higher pasture and clover intakes in cow diets in organic systems. The phytoestrogen composition did not differ between free-range and conventional milk, but free-range milk had more secoisolariciresinol in August. Consuming organic milk would increase intakes of lignans, isoflavones and coumestants but any influence on human health as a result of these differences cannot be concluded from the results of the present work. 

the Free Range Network, for the collection of milk samples. 


\section{References}

Adler, S. A., Purup, S., Hansen-Moller, J., Thuen, E., Gustavsson, A. M., \& Steinshamn, H. (2014). Phyto-oestrogens and their metabolites in milk produced on two pastures with different botanical compositions. Livestock Science, 163, 62-68.

Adler, S. A., Purup, S., Hansen-Moller, J., Thuen, E., \& Steinshamn, H. (2015). Phytoestrogens and Their Metabolites in Bulk-Tank Milk: Effects of Farm Management and Season. Plos One, 10(5).

Adlercreutz, H. (2007). Lignans and human health. Critical Reviews in Clinical Laboratory Sciences, 44(5-6), 483-525.

AHDB. (2011). Grass+: Planning your grazing. In, (pp. 1-19). Kenilworth, UK: Agriculture and Horticulture Development Board.

AHDB. (2012). Feeding+: Managing organic feeding. In, (pp. 1-14). Kenilworth, UK: Agriculture and Horticulture Development Board.

Andersen, C., Weisbjerg, M. R., Hansen-Moller, J., \& Sejrsen, K. (2009). Effect of forage on the content of phyto-oestrogens in bovine milk. Animal, 3(4), 617-622.

Antignac, J. P., Cariou, R., Le Bizec, B., \& Andre, F. (2004). New data regarding phytoestrogens content in bovine milk. Food Chemistry, 87(2), 275-281.

Bates, B., Lennox, A., Prentice, A., Bates, C., Page, P., Nicholson, S., \& Swan, G. (2014). National Diet and Nutrition Survey. Results from Years 1-4 (combined) of the rolling programme (2008/092011/12) (Revised February 2017). In https://www.gov.uk/government/statistics/nationaldiet-and-nutrition-survey-results-from-years-1-to-4-combined-of-the-rolling-programmefor-2008-and-2009-to-2011-and-2012 (Ed.), (pp. 139): Public Health England.

Booth, N. L., Overk, C. R., Yao, P., Totura, S., Deng, Y., Hedayat, A. S., Bolton, J. L., Pauli, G. F., \& Farnsworth, N. R. (2006). Seasonal variation of red clover (Trifolium pratense L., fabaceae) isoflavones and estrogenic activity. Journal of Agricultural and Food Chemistry, 54(4), 12771282.

Butler, G., Nielsen, J. H., Larsen, M. K., Rehberger, B., Stergiadis, S., Canever, A., \& Leifert, C. (2011). The effects of dairy management and processing on quality characteristics of milk and dairy products. NJAS Wageningen Journal of Life Science, 58, 97-102.

Crozier, A. J. I. B. C., N. (2009). Dietary phenolics: chemistry, bioavailability and effects on health. $N P R, 26(8), 965-1096$.

Dewhurst, R. J., Evans, R. T., Scollan, N. D., Moorby, J. M., Merry, R. J., \& Wilkins, R. J. (2003). Comparison of grass and legume silages for milk production. 2. In vivo and in sacco evaluations of rumen function. Journal of Dairy Science, 86(8), 2612-2621.

Fardet, A. (2010). New hypotheses for the health-protective mechanisms of whole-grain cereals: what is beyond fibre? Nutrition Research Reviews, 23(1), 65-134.

Gagnon, N., Cortes, C., da Silva, D., Kazama, R., Benchaar, C., dos Santos, G., Zeoula, L., \& Petit, H. V. (2009). Ruminal metabolism of flaxseed (Linum usitatissimum) lignans to the mammalian lignan enterolactone and its concentration in ruminal fluid, plasma, urine and milk of dairy cows. British Journal of Nutrition, 102(7), 1015-1023.

Gilmour, A. R., Thompson, R., \& Cullis, B. R. (1995). Average information REML: An efficient algorithm for variance parameter estimation in linear mixed models. Biometrics, 51(4), 14401450.

Heinonen, S., Nurmi, T., Liukkonen, K., Poutanen, K., Wahala, K., Deyama, T., Nishibe, S., \& Adlercreutz, H. (2001). In vitro metabolism of plant lignans: New precursors of mammalian lignans enterolactone and enterodiol. Journal of Agricultural and Food Chemistry, 49(7), 3178-3186.

Hoikkala, A., Mustonen, E., Saastamolnen, I., Jokela, T., Taponen, J., Hannu, S., \& Wahala, K. (2007). High levels of equol in organic skimmed Finnish cow milk. Molecular Nutrition \& Food Research, 51(7), 782-786. 
Hojer, A., Adler, S., Purup, S., Hansen-Moller, J., Martinsson, K., Steinshamn, H., \& Gustavsson, A. M. (2012). Effects of feeding dairy cows different legume-grass silages on milk phytoestrogen concentration. Journal of Dairy Science, 95(8), 4526-4540.

Jungbauer, A., \& Medjakovic, S. (2014). Phytoestrogens and the metabolic syndrome. Journal of Steroid Biochemistry and Molecular Biology, 139, 277-289.

Kallela, K., Saastamoinen, I., \& Huokuna, E. (1987). Variations in the content of plant estrogens in red clover timothy-grass during the growing season. Acta Veterinaria Scandinavica, 28(3-4), 255262.

Kuhnle, G. G. C., Delcaqulla, C., Aspinall, S. M., Runswick, S. A., Mulligan, A. A., \& Bingham, S. A. (2008). Phytoestrogen Content of Foods of Animal Origin: Dairy Products, Eggs, Meat, Fish, and Seafood. Journal of Agricultural and Food Chemistry, 56(21), 10099-10104.

Kuhnle, G. G. C., Dell'Aquila, C., Aspinall, S. M., Runswick, S. A., Joosen, A., Mulligan, A. A., \& Bingham, S. A. (2009a). Phytoestrogen content of fruits and vegetables commonly consumed in the UK based on LC-MS and C-13-labelled standards. Food Chemistry, 116(2), 542-554.

Kuhnle, G. G. C., Dell'Aquila, C., Aspinall, S. M., Runswick, S. A., Mulligan, A. A., \& Bingham, S. A. (2009b). Phytoestrogen Content of Cereals and Cereal-Based Foods Consumed in the UK. Nutrition and Cancer-an International Journal, 61(3), 302-309.

Leitzmann, C. (2016). Characteristics and Health Benefits of Phytochemicals. Forschende Komplementarmedizin, 23(2), 69-74.

Mustonen, E. A., Tuori, M., Saastamoinen, I., Taponen, J., Wahala, K., Saloniemi, H., \& Vanhatalo, A. (2009). Equol in milk of dairy cows is derived from forage legumes such as red clover. British Journal of Nutrition, 102(11), 1552-1556.

Niemeyer, H. B., Honig, D. M., Kulling, S. E., \& Metzler, M. (2003). Studies on the metabolism of the plant lignans secoisolariciresinol and matairesinol. Journal of Agricultural and Food Chemistry, 51(21), 6317-6325.

Njastad, K. M., Adler, S. A., Hansen-Moller, J., Thuen, E., Gustavsson, A. M., \& Steinshamn, H. (2014). Gastrointestinal metabolism of phytoestrogens in lactating dairy cows fed silages with different botanical composition. Journal of Dairy Science, 97(12), 7735-7750.

Norskov, N. P., Olsen, A., Tjonneland, A., Bolvig, A. K., Laerke, H. N., \& Knudsen, K. E. B. (2015). Targeted LC-MS/MS Method for the Quantitation of Plant Lignans and Enterolignans in Biofluids from Humans and Pigs. Journal of Agricultural and Food Chemistry, 63(27), 62836292.

Purup, S., Hansen-Møller, J.,Sejrsen, K., Chritsensen, L. P., Lykkesfeldt, A. E., Leffers, H., Skakkebæk, N. E;. (2005). Increased phytoestrogen content in organic milk and the biological importance. In): Newsletter from Danish Research Center Organic.

Reed, K. F. M. (2016). Fertility of Herbivores Consuming Phytoestrogen-containing Medicago and Trifolium Species. Agriculture-Basel, 6(3).

Smeds, A. I., Eklund, P. C., Sjoholm, R. E., Willfor, S. M., Nishibe, S., Deyama, T., \& Holmbom, B. R. (2007). Quantification of a broad spectrum of lignans in cereals, oilseeds, and nuts. Journal of Agricultural and Food Chemistry, 55(4), 1337-1346.

Soil Association. (2018). Organic Standards: Farming and Growing. In S. Association (Ed.), (pp. 258). Bristol, England: Soil Association.

Steinshamn, H., Purup, S., Thuen, E., \& Hansen-Moller, J. (2008). Effects of clover-grass silages and concentrate supplementation on the content of phytoestrogens in dairy cow milk. Journal of Dairy Science, 91(7), 2715-2725.

Stergiadis, S., Berlitz, C. B., Hunt, B., Garg, S., Givens, I., \& Kliem, K. E. (2019). An update to the fatty acid profiles of bovine retail milk in the United Kingdom: implications for nutrition in different age and gender groups. Food Chemistry, 276, 218-230.

Stergiadis, S., Hynes, D. N., Thomson, A. L., Kliem, K. E., Berlitz, C. G., Günal, M., \& Yan, T. (2018). Effect of substituting fresh-cut perennial ryegrass with fresh-cut white clover on bovine milk fatty acid profile. Journal of the Science of Food and Agriculture, 98(10), 3982-3993. 
Stergiadis, S., Leifert, C., Seal, C. J., Eyre, M. D., Larsen, M. K., Slots, T., Nielsen, J. H., \& Butler, G. (2015). A 2-year study on milk quality from three pasture-based dairy systems of contrasting production intensities in Wales. Journal of Agricultural Science, 153(4), 708-731.

Stergiadis, S., Leifert, C., Seal, C. J., Eyre, M. D., Nielsen, J. H., Larsen, M. K., Slots, T., Steinshamn, H., \& Butler, G. (2012). Effect of feeding intensity and milking system on nutritionally relevant milk components in dairy farming systems in the north east of England. Journal of Agricultural and Food Chemistry, 60, 7270-7281.

Thorning, T. K., Raben, A., Tholstrup, T., Soedamah-Muthu, S. S., Givens, I., \& Astrup, A. (2016). Milk and dairy products: good or bad for human health? An assessment of the totality of scientific evidence. Food Nutr Res, 60, 32527.

Tsao, R., Papadopoulos, Y., Yang, R., Young, J. C., \& McRae, K. (2006). Isoflavone profiles of red clovers and their distribution in different parts harvested at different growing stages. Journal of Agricultural and Food Chemistry, 54(16), 5797-5805.

Wang, X., Ouyang, Y. Y., Liu, J., \& Zhao, G. (2014). Flavonoid intake and risk of CVD: a systematic review and meta-analysis of prospective cohort studies. British Journal of Nutrition, 111(1), $1-11$. 
Table 2

Effect of sampling month on the concentrations of lignans and isoflavones (means and SE) in retail milk samples collected monthly over 12 months

\begin{tabular}{|c|c|c|c|c|c|c|c|c|c|c|c|c|c|c|}
\hline \multirow[b]{2}{*}{ Phytoestrogens (ng/ml) } & \multicolumn{12}{|c|}{ Month $^{a}$} & \multirow[b]{2}{*}{ SE } & \multirow{2}{*}{$\begin{array}{l}\text { ANOVA } \\
\text { P-values }\end{array}$} \\
\hline & March & April & May & June & July & August & September & October & November & December & January & February & & \\
\hline \multicolumn{15}{|l|}{ Plant lignans } \\
\hline Secoisolariciresinol & $0.11^{\mathrm{E}}$ & $0.12^{\mathrm{E}}$ & $0.22^{\mathrm{AB}}$ & $0.17^{\mathrm{C}}$ & $0.26^{\mathrm{A}}$ & $0.24^{\mathrm{A}}$ & $0.20^{\mathrm{BC}}$ & $0.17^{\mathrm{CD}}$ & $0.11^{\mathrm{E}}$ & $0.13^{\mathrm{E}}$ & $0.13^{\mathrm{DE}}$ & $0.12^{\mathrm{E}}$ & 0.016 & $* * *$ \\
\hline Matairesinol & $0.10^{\mathrm{D}}$ & $0.12^{\mathrm{CD}}$ & $0.23^{\mathrm{A}}$ & $0.18^{\mathrm{B}}$ & $0.19^{\mathrm{B}}$ & $0.18^{\mathrm{B}}$ & $0.17^{\mathrm{B}}$ & $0.14^{\mathrm{C}}$ & $0.10^{\mathrm{CD}}$ & $0.12^{\mathrm{CD}}$ & $0.10^{\mathrm{D}}$ & $0.11^{\mathrm{CD}}$ & 0.013 & $* * *$ \\
\hline Lariciresinol & $0.34^{\mathrm{DEF}}$ & $0.32^{\mathrm{EF}}$ & $0.41^{\mathrm{BC}}$ & $0.39^{\mathrm{CD}}$ & $0.50^{\mathrm{A}}$ & $0.48^{\mathrm{A}}$ & $0.50^{\mathrm{A}}$ & $0.47^{\mathrm{AB}}$ & $0.39^{\mathrm{CD}}$ & $0.38^{\mathrm{CDE}}$ & $0.33^{\mathrm{EF}}$ & $0.30^{\mathrm{F}}$ & 0.033 & $* * *$ \\
\hline Hydroxymatairesinol & $0.24^{\mathrm{A}}$ & $0.16^{\mathrm{CD}}$ & $0.19^{\mathrm{BCD}}$ & $0.16^{\mathrm{D}}$ & $0.16^{\mathrm{D}}$ & $0.16^{\mathrm{D}}$ & $0.15^{\mathrm{D}}$ & $0.18^{\mathrm{BCD}}$ & $0.18^{\mathrm{BCD}}$ & $0.23^{\mathrm{AB}}$ & $0.23^{\mathrm{A}}$ & $0.21^{\mathrm{ABC}}$ & 0.020 & $* *$ \\
\hline Sum of plant lignans & $0.79^{\mathrm{DEF}}$ & $0.72^{\mathrm{F}}$ & $1.05^{\mathrm{AB}}$ & $0.91^{\mathrm{CD}}$ & $1.11^{\mathrm{A}}$ & $1.06^{\mathrm{A}}$ & $1.02^{\mathrm{AB}}$ & $0.96^{\mathrm{BC}}$ & $0.78^{\mathrm{EF}}$ & $0.86^{\mathrm{CDE}}$ & $0.79^{\mathrm{DEF}}$ & $0.72^{\mathrm{F}}$ & 0.059 & $* * *$ \\
\hline \multicolumn{15}{|l|}{ Mammalian lignans } \\
\hline Enterolactone & $54.4^{\mathrm{CDE}}$ & $58.1^{\mathrm{BCD}}$ & $80.6^{\mathrm{A}}$ & $78.5^{\mathrm{A}}$ & $75.0^{\mathrm{A}}$ & $65.7^{\mathrm{B}}$ & $59.8^{\mathrm{BC}}$ & $59.7^{\mathrm{BC}}$ & $55.7^{\mathrm{BCD}}$ & $54.9^{\mathrm{CDE}}$ & $49.2^{\mathrm{DE}}$ & $46.7^{\mathrm{E}}$ & 3.96 & $* * *$ \\
\hline Enterodiol & $0.32^{\mathrm{CDE}}$ & $0.28^{\mathrm{EF}}$ & $0.44^{\mathrm{A}}$ & $0.33^{\mathrm{DE}}$ & $0.38^{\mathrm{BCD}}$ & $0.37^{\mathrm{BCD}}$ & $0.40^{\mathrm{AB}}$ & $0.37^{\mathrm{BC}}$ & $0.29^{\mathrm{EF}}$ & $0.32^{\mathrm{CDE}}$ & $0.31^{\mathrm{CDE}}$ & $0.26^{\mathrm{F}}$ & 0.029 & $* * *$ \\
\hline Sum of mammalian lignans & $54.7^{\mathrm{CDE}}$ & $58.4^{\mathrm{BCD}}$ & $81.0^{\mathrm{A}}$ & $78.8^{\mathrm{A}}$ & $75.3^{\mathrm{A}}$ & $66.0^{\mathrm{B}}$ & $60.2^{\mathrm{BC}}$ & $60.1^{\mathrm{BC}}$ & $56.0^{\mathrm{BCD}}$ & $55.2^{\mathrm{CDE}}$ & $49.6^{\mathrm{DE}}$ & $47.0^{\mathrm{E}}$ & 3.978 & $* * *$ \\
\hline Sum of lignans & $55.5^{\mathrm{CDE}}$ & $59.2^{\mathrm{CD}}$ & $82.1^{\mathrm{A}}$ & $79.7^{\mathrm{A}}$ & $76.5^{\mathrm{A}}$ & $67.1^{\mathrm{B}}$ & $61.2^{\mathrm{BC}}$ & $61.0^{\mathrm{BC}}$ & $56.8^{\mathrm{BCD}}$ & $56.0^{\mathrm{CDE}}$ & $50.3^{\mathrm{DE}}$ & $47.7^{\mathrm{E}}$ & 3.994 & $* * *$ \\
\hline \multicolumn{15}{|l|}{ Plant isoflavones } \\
\hline Daidzein & $1.84^{\mathrm{AB}}$ & $1.51^{\mathrm{ABC}}$ & $1.53^{\mathrm{ABC}}$ & $1.11^{\mathrm{D}}$ & $1.62^{\mathrm{ABC}}$ & $1.93^{\mathrm{A}}$ & $1.92^{\mathrm{AB}}$ & $2.04^{\mathrm{A}}$ & $1.72^{\mathrm{ABC}}$ & $1.61^{\mathrm{ABC}}$ & $1.52^{\mathrm{BCD}}$ & $1.45^{\mathrm{CD}}$ & 0.308 & $* * *$ \\
\hline Genistein & $1.95^{\mathrm{A}}$ & $1.47^{\mathrm{B}}$ & $1.01^{\mathrm{CD}}$ & $0.94^{\mathrm{D}}$ & $1.37^{\mathrm{BCD}}$ & $1.46^{\mathrm{BC}}$ & $1.48^{\mathrm{BC}}$ & $1.60^{\mathrm{AB}}$ & $1.71^{\mathrm{AB}}$ & $1.37^{\mathrm{BCD}}$ & $1.32^{\mathrm{BCD}}$ & $1.51^{\mathrm{BC}}$ & 0.283 & $* * *$ \\
\hline Glycitein & $2.55^{\mathrm{A}}$ & $2.41^{\mathrm{AB}}$ & $2.52^{\mathrm{ABC}}$ & $1.62^{\mathrm{F}}$ & $1.81^{\mathrm{EF}}$ & $2.25^{\mathrm{BCD}}$ & $2.09^{\mathrm{CDEF}}$ & $2.17^{\mathrm{BCDE}}$ & $2.01^{\mathrm{DEF}}$ & $2.03^{\mathrm{DEF}}$ & $2.24^{\mathrm{BCDE}}$ & $2.17^{\mathrm{BCDE}}$ & 0.194 & $* * *$ \\
\hline Formononetin & $0.65^{\mathrm{A}}$ & $0.47^{\mathrm{ABC}}$ & $0.29^{\mathrm{BC}}$ & $0.26^{\mathrm{C}}$ & $0.43^{\mathrm{ABC}}$ & $0.57^{\mathrm{A}}$ & $0.53^{\mathrm{ABC}}$ & $0.53^{\mathrm{AB}}$ & $0.64^{\mathrm{A}}$ & $0.49^{\mathrm{ABC}}$ & $0.49^{\mathrm{ABC}}$ & $0.51^{\mathrm{ABC}}$ & 0.182 & $*$ \\
\hline Naringenin & 0.35 & 0.25 & 0.25 & 0.20 & 0.25 & 0.22 & 0.21 & 0.19 & 0.18 & 0.19 & 0.21 & 0.20 & 0.032 & $\dagger$ \\
\hline Sum of plant isoflavones & $7.33^{\mathrm{A}}$ & $6.11^{\mathrm{AB}}$ & $5.59^{\mathrm{B}}$ & $4.13^{\mathrm{C}}$ & $5.48^{\mathrm{B}}$ & $6.43^{\mathrm{AB}}$ & $6.22^{\mathrm{AB}}$ & $6.53^{\mathrm{AB}}$ & $6.25^{\mathrm{B}}$ & $5.70^{\mathrm{B}}$ & $5.78^{\mathrm{B}}$ & $5.85^{\mathrm{B}}$ & 0.863 & $* * *$ \\
\hline \multicolumn{15}{|l|}{ Mammalian isoflavones } \\
\hline Equol & $252.0^{\mathrm{AB}}$ & $195.4^{\mathrm{BCD}}$ & $85.7^{\mathrm{F}}$ & $111.8^{\mathrm{EF}}$ & $103.4^{\mathrm{EF}}$ & $149.7^{\mathrm{DE}}$ & $183.3^{\mathrm{CD}}$ & $236.1^{\mathrm{ABC}}$ & $297.4^{\mathrm{A}}$ & $274.9^{\mathrm{AB}}$ & $264.8^{\mathrm{AB}}$ & $283.1^{\mathrm{A}}$ & 61.09 & $* * *$ \\
\hline Sum of isoflavones & $259.4^{\mathrm{AB}}$ & $201.5^{\mathrm{BCD}}$ & $91.3^{\mathrm{F}}$ & $115.9^{\mathrm{EF}}$ & $108.8^{\mathrm{EF}}$ & $156.1^{\mathrm{DE}}$ & $189.5^{\mathrm{CD}}$ & $242.7^{\mathrm{ABC}}$ & $303.7^{\mathrm{A}}$ & $280.6^{\mathrm{AB}}$ & $270.5^{\mathrm{AB}}$ & $288.9^{\mathrm{A}}$ & 61.88 & $* * *$ \\
\hline \multicolumn{15}{|l|}{ Plant coumestants } \\
\hline Coumestrol & 0.26 & 0.22 & 0.35 & 0.18 & 0.23 & 0.17 & 0.18 & 0.22 & 0.26 & 0.27 & 0.23 & 0.25 & 0.069 & ns \\
\hline
\end{tabular}

${ }^{a} \mathrm{n}=10$, for each month

$b * * *, \mathrm{P}<0.001 ; * *, \mathrm{P}<0.01 ; *, \mathrm{P}<0.05 ; \dagger, 0.05<\mathrm{P}<0.10$ (trend); ns, $\mathrm{P}>0.10$. Different upper case letters within a row indicate significant differences between sampling month means (Fisher's Least Significant Difference test; $\mathrm{P}<0.05$ ) 

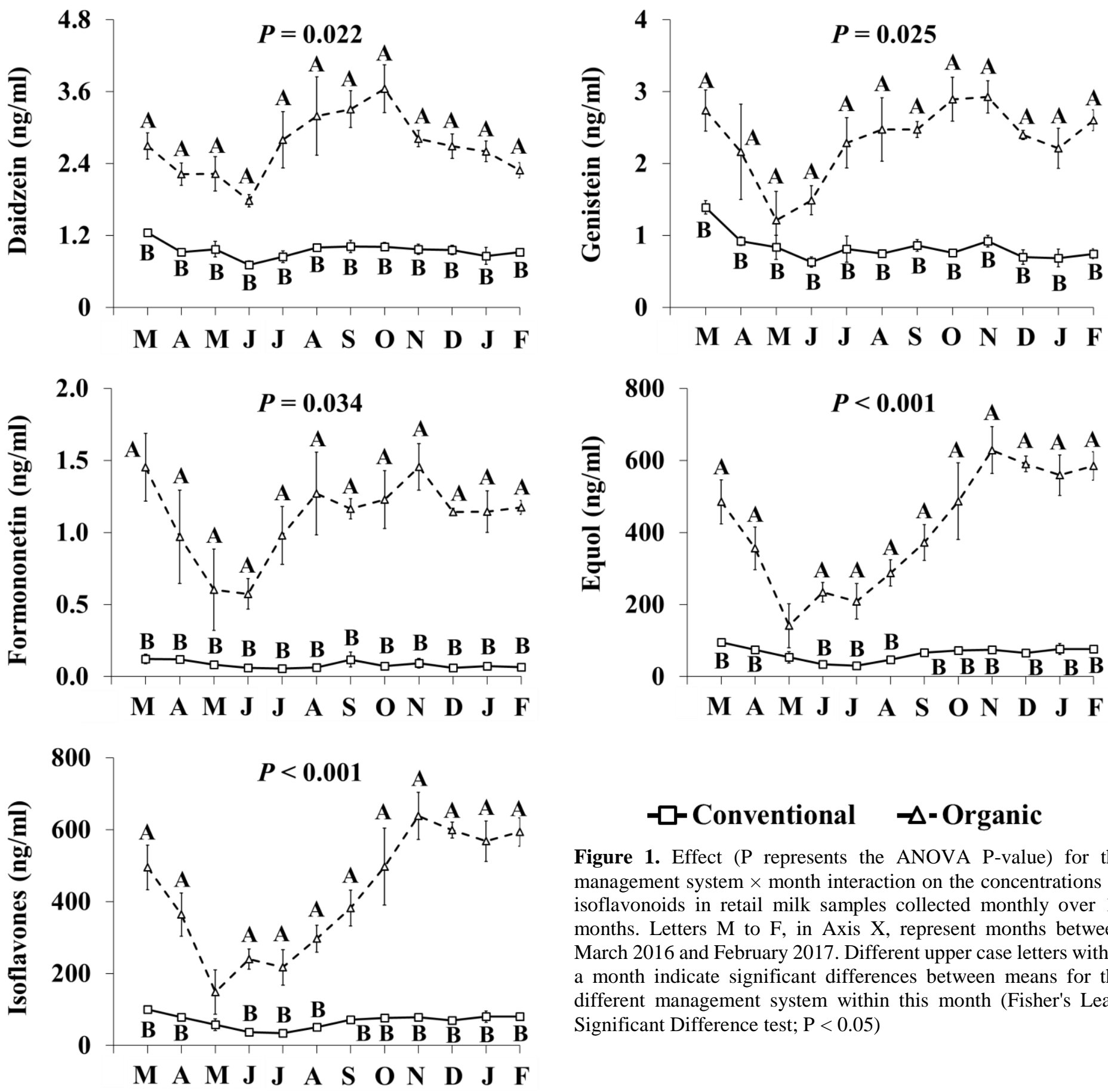

\section{$-\square$-Conventional $\quad-\Delta$-Organic}

Figure 1. Effect ( $\mathrm{P}$ represents the ANOVA $\mathrm{P}$-value) for the management system $\times$ month interaction on the concentrations of isoflavonoids in retail milk samples collected monthly over 12 months. Letters $\mathrm{M}$ to $\mathrm{F}$, in Axis $\mathrm{X}$, represent months between March 2016 and February 2017. Different upper case letters within a month indicate significant differences between means for the different management system within this month (Fisher's Least Significant Difference test; $\mathrm{P}<0.05$ ) 

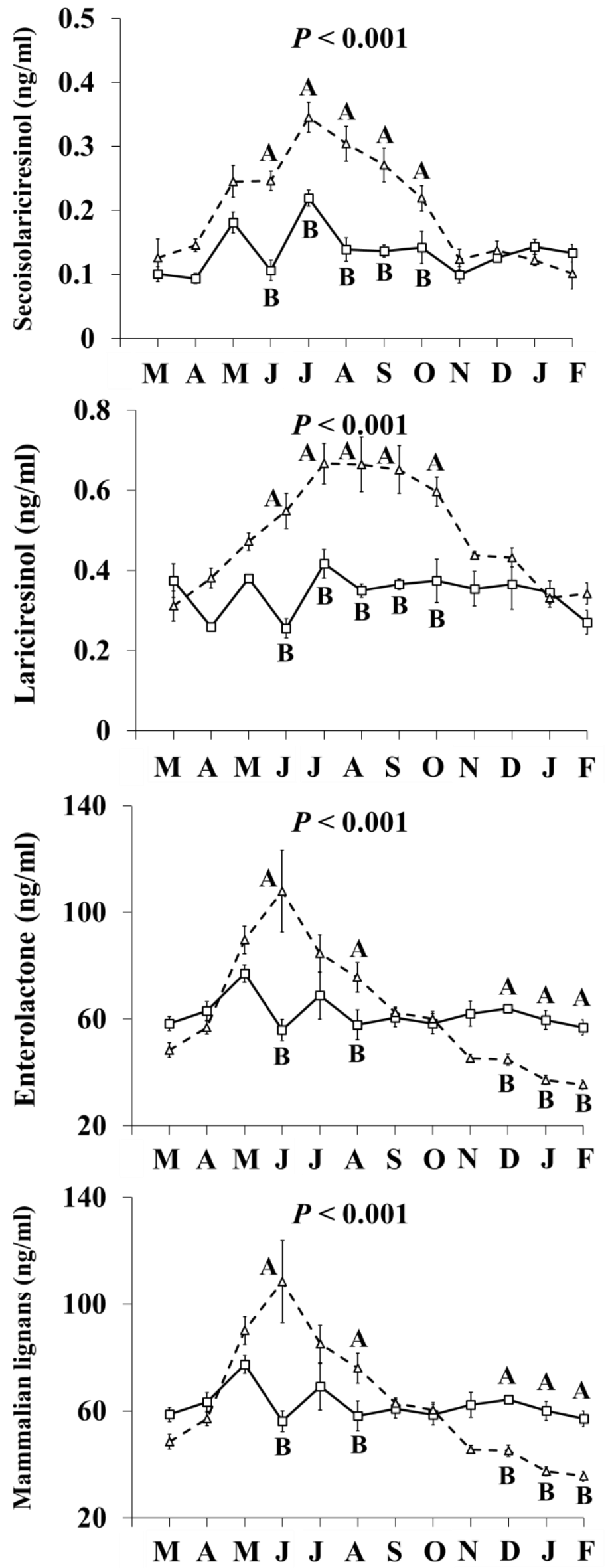
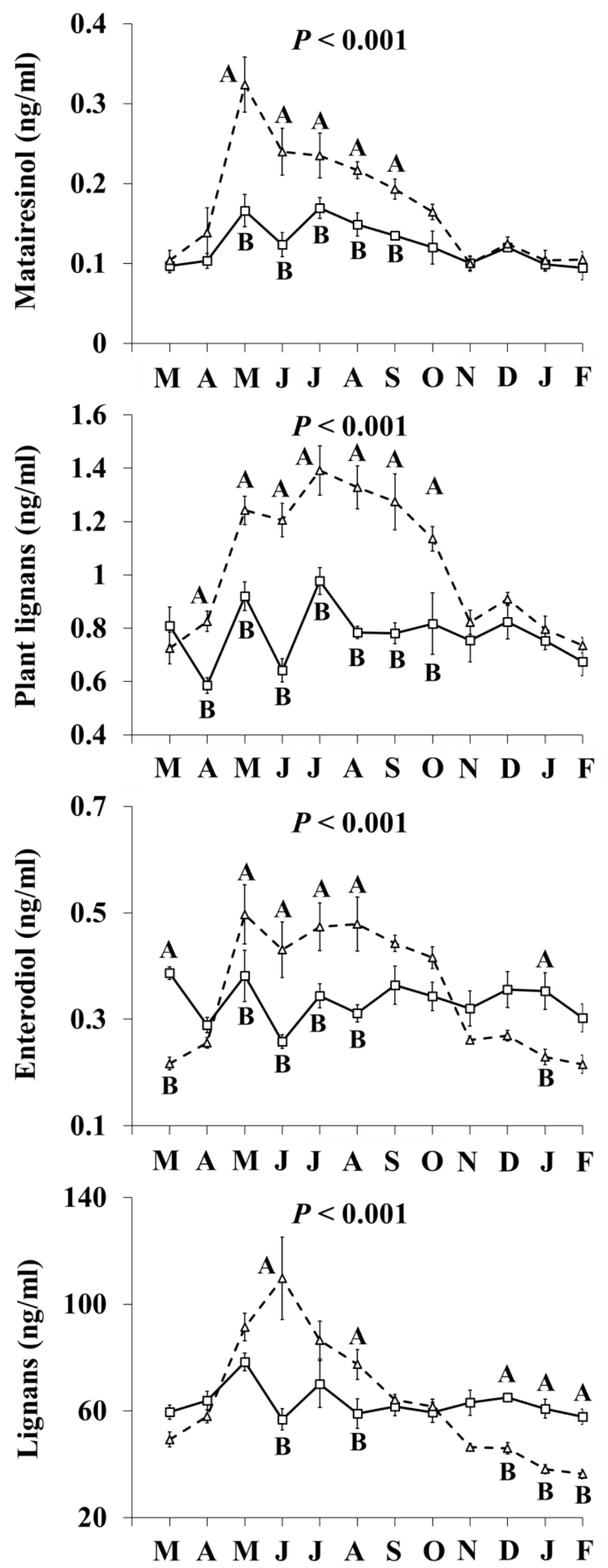


\section{$-\square$-Conventional $\quad-\Delta$-Organic}

Figure 2. Effect (P represents the ANOVA P-value) for the management system $\times$ month interaction on the concentrations of lignans in retail milk samples collected monthly over 12 months. Letters M to F, in Axis X, represent months between March 2016 and February 2017. Different upper case letters within a month indicate significant differences between means for the different management system within this month (Fisher's Least Significant Difference test; $\mathrm{P}<0.05$ ) 


\section{APPENDIX}

Table A1. Compound-Dependent LC-MS/MS Parameter, Declustering Potential (DP), Entrance Potential (EP), Collision Energy (CE) and Cell Exit Potential (CEP).

\begin{tabular}{lcccccc}
\hline Parameter assessed & $\begin{array}{c}\text { Q1 mass } \\
(\mathbf{m} / \mathbf{z})\end{array}$ & $\begin{array}{c}\mathbf{Q 3} \text { mass } \\
(\mathbf{m} / \mathbf{z})\end{array}$ & $\begin{array}{c}\mathbf{D P} \\
\mathbf{( V )}\end{array}$ & $\begin{array}{c}\mathbf{E P} \\
(\mathbf{V})\end{array}$ & $\begin{array}{c}\mathbf{C E} \\
(\mathbf{e V})\end{array}$ & $\begin{array}{c}\text { CEP } \\
(\mathbf{V})\end{array}$ \\
\hline${ }^{13} \mathrm{C}_{3}$-enterolactone & 300.0 & 191.9 & -128 & -10 & -30 & -14 \\
${ }^{13} \mathrm{C}_{3}$-enterodiol & 304.1 & 255.1 & -140 & -10 & -32 & -17 \\
Enterolactone & 297.1 & 189.1 & -140 & -10 & -26 & -21 \\
Enterodiol & 301.1 & 253.1 & -140 & -10 & -32 & -19 \\
Matairesinol & 357.2 & 82.9 & -145 & -10 & -26 & -7 \\
Hydroxymatairesinol & 373.1 & 217.1 & -115 & -10 & -32 & -13 \\
Secoisolariciresinol & 361.2 & 165.0 & -150 & -10 & -34 & -11 \\
Lariciresinol & 359.1 & 329.0 & -40 & -10 & -16 & -21 \\
Isolariciresinol & 359.2 & 344.0 & -165 & -10 & -26 & -31 \\
Pinoresinol & 357.2 & 151.0 & -155 & -10 & -24 & -11 \\
Syringaresinol & 417.1 & 181.0 & -170 & -10 & -26 & -13 \\
Medioresinol & 387.2 & 151.0 & -15 & -10 & -26 & -25 \\
Equol-d4 & 245.1 & 122.9 & -75 & -10 & -20 & -15 \\
Daidzein-d3 & 256.0 & 225.9 & -165 & -10 & -42 & -13 \\
Genistein-d4 & 273.1 & 135.1 & -150 & -10 & -43 & -11 \\
Equol & 241.1 & 119.0 & -70 & -10 & -26 & -8 \\
Equol qualifier & 241.1 & 134.9 & -70 & -10 & -25 & -8 \\
Daidzein & 253.0 & 223.0 & -171 & -10 & -42 & -15 \\
Genistein & 269.0 & 132.8 & -160 & -10 & -42 & -16 \\
Glycitein & 283.0 & 267.9 & -75 & -10 & -25 & -16 \\
Naringenin & 271.1 & 150.9 & -121 & -10 & -25 & -18 \\
Formononetin & 267.0 & 251.9 & -147 & -10 & -28 & -15 \\
Chrysin & 253.1 & 142.9 & -128 & -10 & -30 & -14 \\
Coumestrol & 267.0 & 211.0 & -176 & -10 & -40 & -11 \\
Coumestrol qualifier & 267.0 & 134.9 & -176 & -10 & -39 & -12 \\
\hline
\end{tabular}


Table A2. Low Limit of Quantitation (LLOQ) and Upper Limit of Quantitation (ULOQ) and their Corresponding Regression Coefficients $(r)$.

\begin{tabular}{lccc}
\hline Parameter assessed & $\begin{array}{c}\text { LLOQ Nm } \\
(\mathbf{n g} / \mathbf{m L})\end{array}$ & $\begin{array}{c}\text { ULOQ Nm } \\
(\mathbf{n g} / \mathbf{m L})\end{array}$ & $\boldsymbol{r}$ \\
\hline Equol & $1.6(0.39)$ & $412.8(100)$ & 0.9958 \\
Daidzein & $0.038(0.00977)$ & $39.3(10)$ & 0.9991 \\
Genistein & $0.072(0.0195)$ & $37.0(10)$ & 0.9997 \\
Glycitein & $0.034(0.00977)$ & $35.2(10)$ & 0.9964 \\
Naringenin & $0.036(0.00977)$ & $36.6(10)$ & 0.9998 \\
Formononetin & $0.0089(0.0024)$ & $9.3(2.5)$ & 0.9998 \\
Chrysin & $0.049(0.00195)$ & $39.3(10)$ & 0.9996 \\
Coumestrol & $0.036(0.00977)$ & $37.2(10)$ & 0.9996 \\
\hline
\end{tabular}




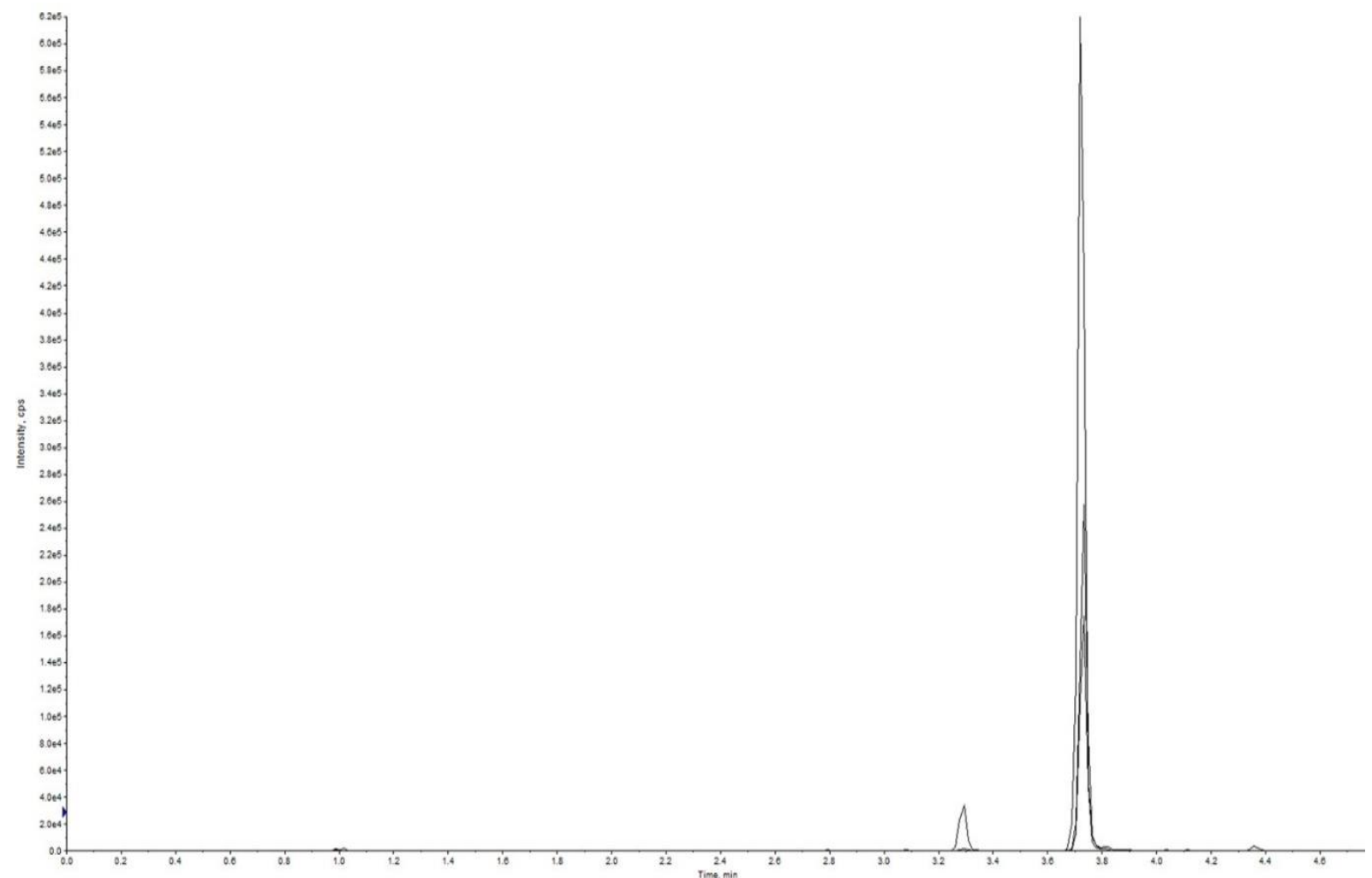

Figure A1. Total Ion Chromatogram of equol and internal standard equol-d4 in concentration of $100 \mathrm{ng} / \mathrm{mL}$ and $200 \mathrm{ng} / \mathrm{mL}$ respectively. Retention time of equol quantifier/qualifier 3.73 and equol-d4 $3.72 \mathrm{~min}$. 


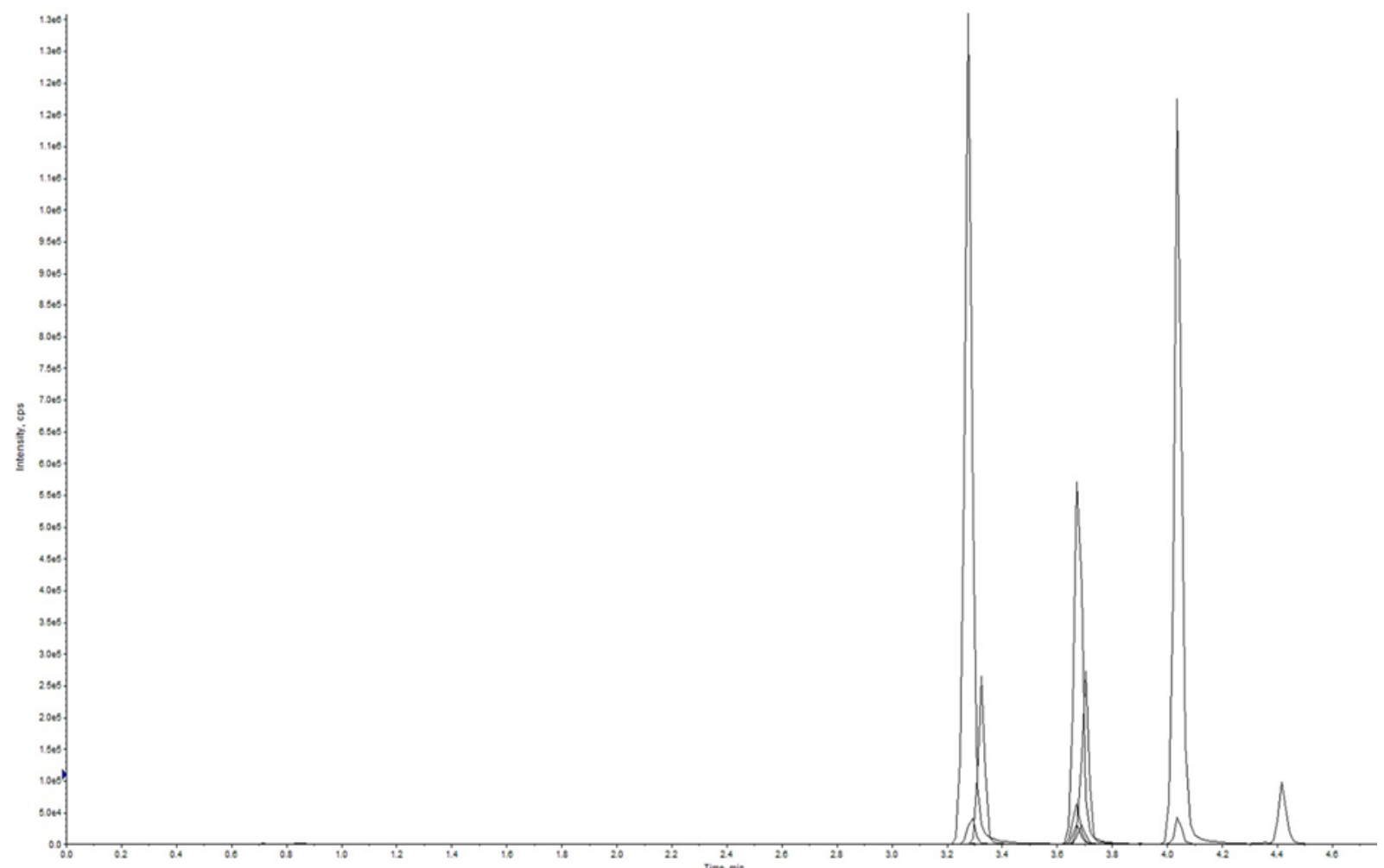

Figure A2. Total Ion Chromatogram of isoflavones standards in concentration of $1.25 \mathrm{ng} / \mathrm{mL}$. The concentration of internal standards Daidzein-d3 and Genistein-d4 were 60 and $30 \mathrm{ng} / \mathrm{mL}$ respectively. Retention time in minutes for the standards were: Daidzein 3.28, Daidzein d4 3.28, Glycitein 3.32, Coumestrol quantifier/qualifier 3.67, Genistein 3.69, Genistein-d4 3.69, Naringenin 3.70, Formononetin 4.04 and Chrysin 4.42 


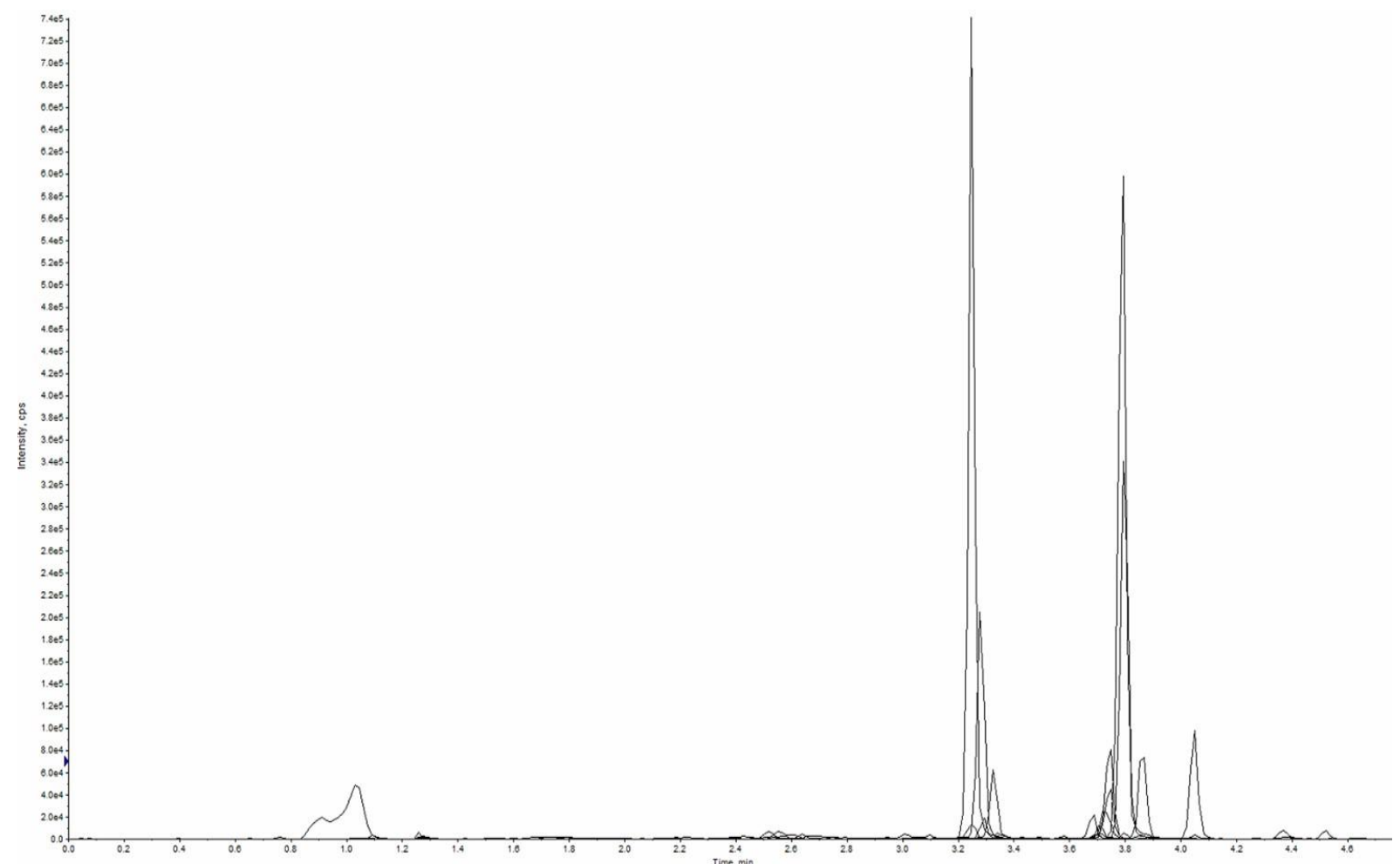

Figure A3. Total Ion Chromatogram of a milk sample for lignans and isoflavones and their corresponding internal standards. 

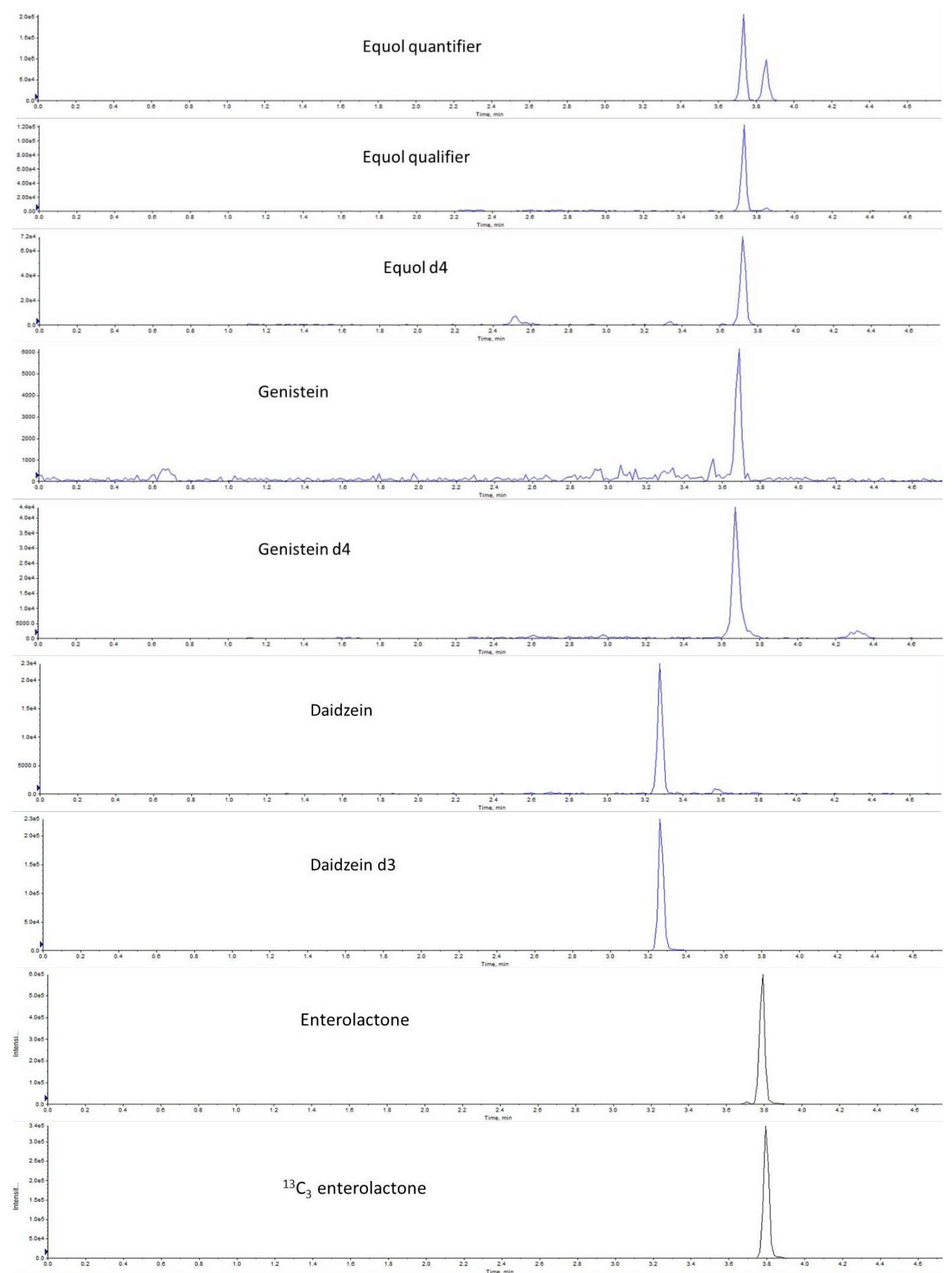

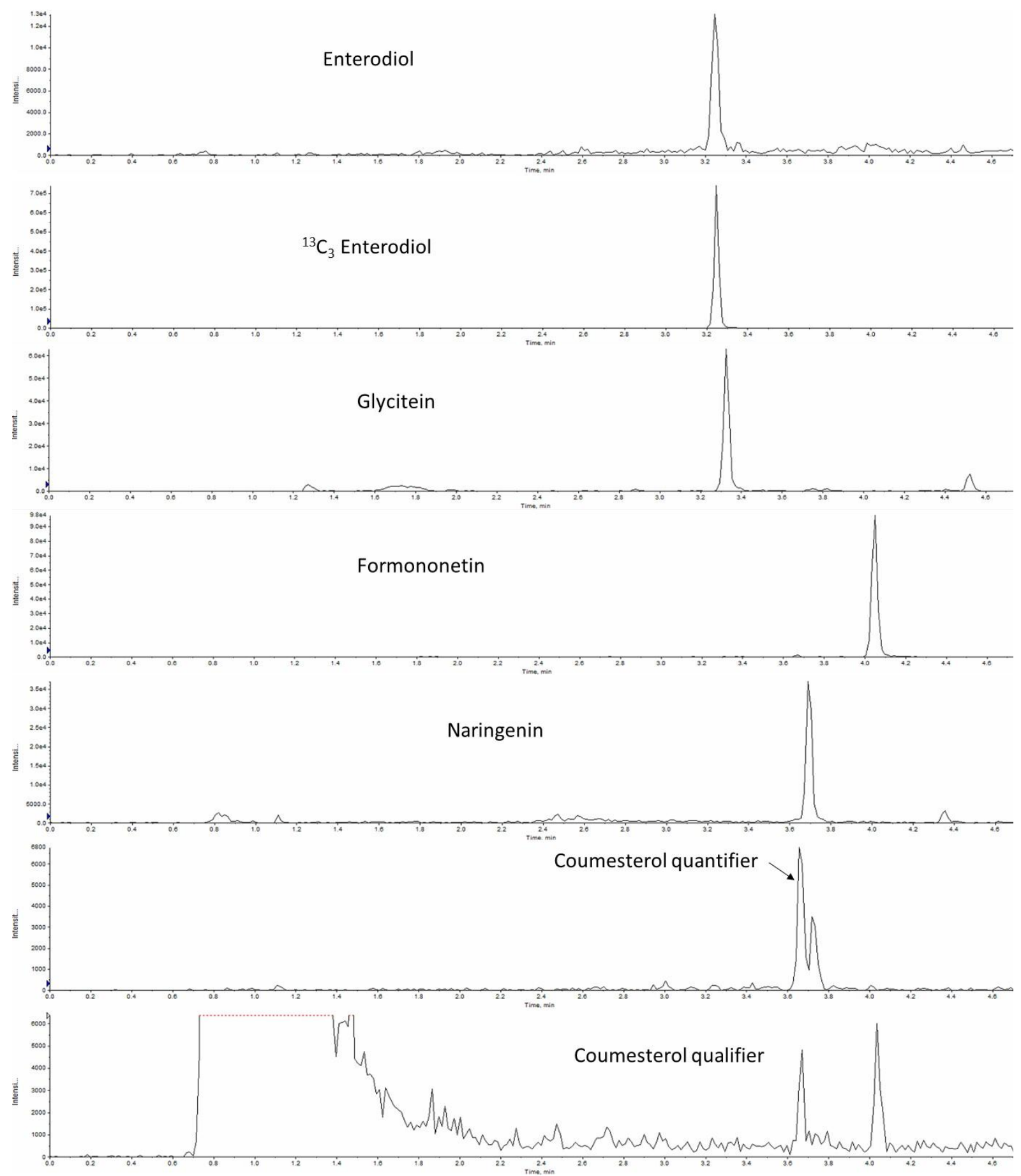

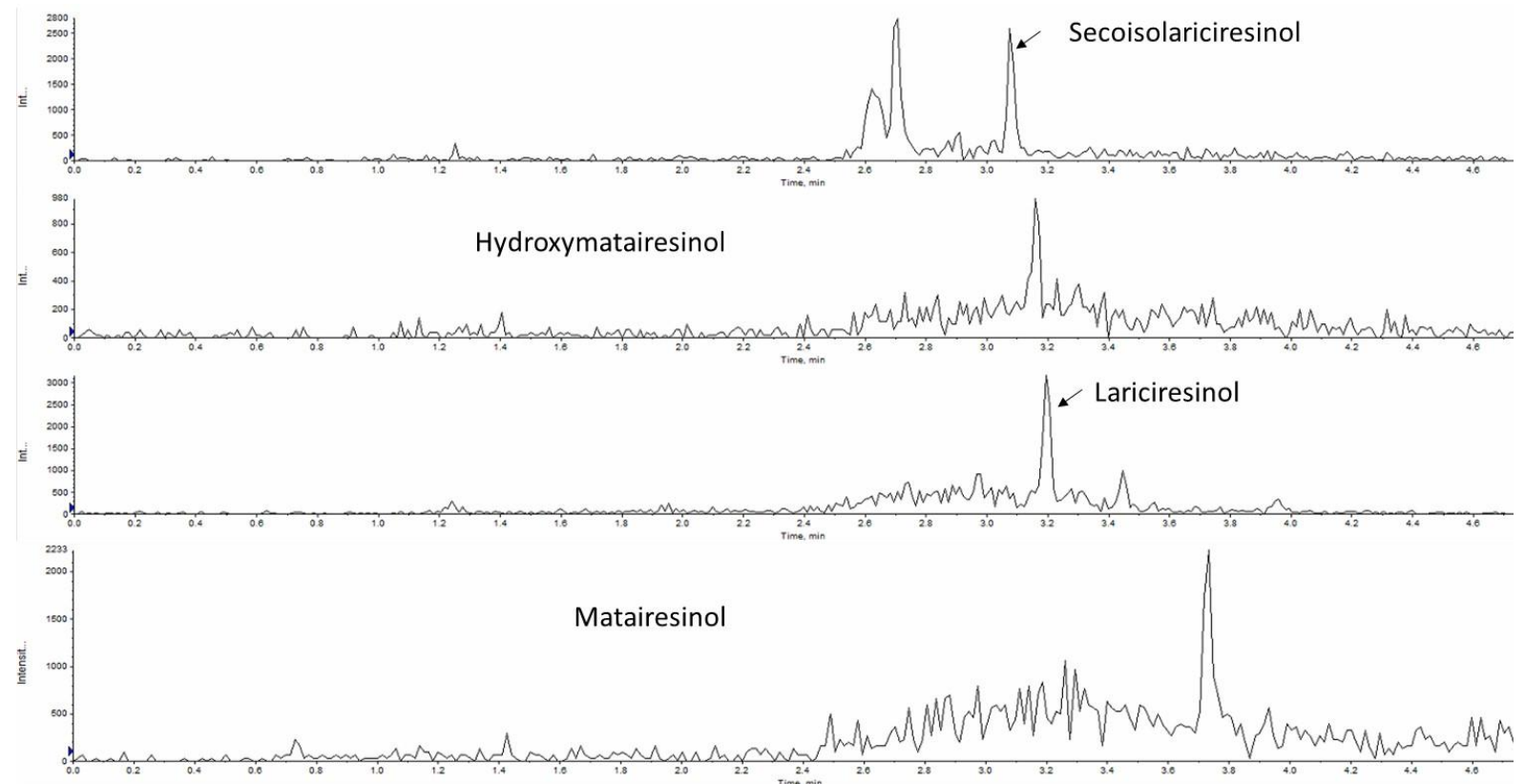

Figure A4. Extracted Ion Chromatograms of lignans and isovlavones and their corresponding internal standards in a milk sample. 